\title{
Assessment of Multiple Mission Reusable Launch Vehicles
}

\author{
Martin Sippel, Sven Stappert, Aaron Koch \\ Martin.Sippel@dlr.de Tel.+49-421-244201145 \\ Space Launcher Systems Analysis (SART), DLR, Bremen, Germany
}

\begin{abstract}
Multiple mission reusable launch vehicles could be an interesting and attractive option of the future with cost saving potential. A similar RLV-configuration capable of fulfilling very different needs might significantly reduce the development effort compared to individual developments of several dedicated crafts.

The announcement of Elon Musk on the imminent development of a fully reusable two-stage launcher to LEO of very large size, called "BFR" is one spectacular example. DLR's SpaceLiner concept is similar in certain aspects to the idea of multiple mission reusable launch vehicles. While in its primary role conceived as an ultrafast intercontinental passenger transport, in its second role the SpaceLiner is intended as an RLV capable of delivering heavy payloads into orbit.
\end{abstract}

The paper provides multidisciplinary technical analyses of the different proposed multi-mission RLV-concepts. The characteristic flight conditions of winged gliding stages with those of rocket-decelerated vertical landing vehicles are compared. Performance, size and safety aspects are evaluated.

Keywords: RLV, BFR, SpaceLiner, TSTO, rocket-propulsion

\begin{tabular}{|c|c|}
\hline & Nomenclature \\
\hline $\mathrm{D}$ & Drag \\
\hline $\mathrm{I}_{\mathrm{sp}}$ & (mass) specific Impulse \\
\hline $\mathrm{L}$ & Lift \\
\hline M & Mach-number \\
\hline $\mathrm{T}$ & Thrust \\
\hline $\mathrm{W}$ & weight \\
\hline g & gravity acceleration \\
\hline $\mathrm{m}$ & mass \\
\hline q & dynamic pressure \\
\hline $\mathrm{v}$ & velocity \\
\hline$\alpha$ & angle of attack \\
\hline \multirow[t]{2}{*}{$\gamma$} & flight path angle \\
\hline & Subscripts, Abbreviations \\
\hline $\mathrm{AOA}$ & Angle of Attack \\
\hline ATM & Air Traffic Management \\
\hline BFR & Big Falcon Rocket \\
\hline BFS & BFR ship \\
\hline CAD & Computer Aided Design \\
\hline DOF & Degree of Freedom \\
\hline DRL & Down-Range Landing site \\
\hline GLOW & Gross Lift-Off Mass \\
\hline ITS & Interplanetary Transport System \\
\hline LEO & Low Earth Orbit \\
\hline LH2 & Liquid Hydrogen \\
\hline LOX & Liquid Oxygen \\
\hline MECO & Main Engine Cut Off \\
\hline MR & Mixture Ratio \\
\hline MRR & Mission Requirements Review \\
\hline NPSP & Net Positive Suction Pressure \\
\hline RCS & Reaction Control System \\
\hline RLV & Reusable Launch Vehicle \\
\hline
\end{tabular}

$\begin{array}{lll} & \text { RTLS } & \text { Return To Launch Site } \\ & \text { SI } & \text { Structural Index } \\ \mathrm{N} & \text { SLME } & \text { SpaceLiner Main Engine } \\ \mathrm{s}(\mathrm{N} \mathrm{s} / \mathrm{kg}) & \text { TAEM } & \text { Terminal Area Energy Management } \\ \mathrm{N} & \text { TPS } & \text { Thermal Protection System } \\ - & \text { TRL } & \text { Technology Readiness Level } \\ \mathrm{N} & \text { TSTO } & \text { Two-Stage-To-Orbit } \\ \mathrm{N} & \text { TVC } & \text { Thrust Vector Control } \\ \mathrm{m} / \mathrm{s}^{2} & \text { CoG } & \text { center of gravity } \\ \mathrm{kg} & \text { Cop } & \text { center of pressure }\end{array}$

$\mathrm{m} / \mathrm{s} \quad 1$ INTRODUCTION

Recently, the launcher development has become highly dynamic again. Major technical successes are achieved in rapid succession. Key players are the US companies SpaceX and Blue Origin. Falcon 9 is now routinely returning the used first stages with high accuracy back to Earth. The successful first launch of Falcon Heavy is another impressive achievement with almost synchronized landing of the two side boosters. Blue Origin demonstrated reuse of suborbital stages with New Shepherd and is now working on a much larger, partially reusable launcher New Glenn.

The ultimate challenge is raised by the announcement of Elon Musk at the IAC 2017 in Adelaide, South Australia of intending, as soon as possible, the development of a fully reusable two-stage launcher to LEO of very large size, called "BFR". This vehicle should be more than a classical launch system with payload release in orbit. Besides delivering heavy cargo up to $150 \mathrm{t}$, the BFR is planned as an interplanetary manned space-ship and as an ultrafast rocket-based point-to-point transport on Earth. [1] These are quite diverse missions to be served by the same or at least similar vehicle.

Multiple mission reusable launch vehicles could be an interesting and attractive option of the future with cost 
saving potential. A similar RLV-configuration capable of fulfilling very different needs might significantly reduce the development effort compared to individual developments of several dedicated crafts. Further, production reaches higher numbers for the same type which likely has a positive impact on manufacturing expenses.

However, the technical side of the multiple mission reusable launch vehicles might be very demanding. Overstretching the mandatory technical requirements to fulfill diverse tasks has a detrimental effect on cost savings. An appropriate compromise is to be looked for.

The probably most spectacular application of the multiple mission reusable launch vehicles which also could generate most of the commercial revenue is the role as ultrafast intercontinental passenger transport. Both example concepts of this paper use vertical launch like all rockets, however, Figure 1 and Figure 2 summarize in a graphical representation the key difference in selected landing modes. BFR is announced to have also vertical landing using its main propulsion system (Figure 1) while the SpaceLiner has been designed for horizontal touch-down on a runway after its hypersonic reentry gliding (Figure 2).

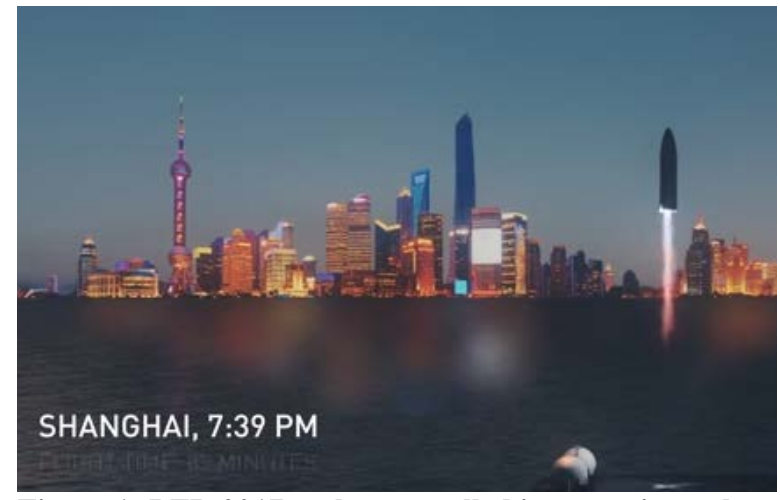

Figure 1: BFR 2017 rocket-propelled intercontinental passenger transport in vertical landing mode from SpaceX video animation [2]

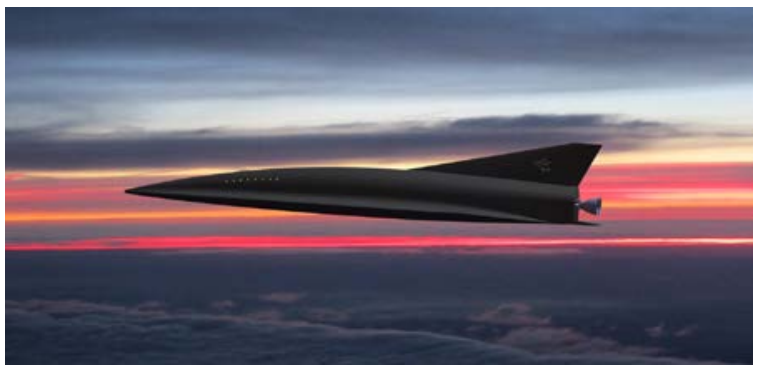

Figure 2: The SpaceLiner rocket-propelled intercontinental passenger transport in final horizontal landing approach

The classical space transportation role of satellite deployment in orbit by the two different kind of fully reusable TSTO is highlighting their multiple mission capabilities. (Figure 3 and Figure 4) Musk's vision of "Making Life Multi-Planetary" is represented in Figure 5 with BFS placed on Mars. Such technically even more demanding role of a multi-mission vehicle is not yet intended by the SpaceLiner concept and its large wing would not be the best technical choice for the interplanetary application.

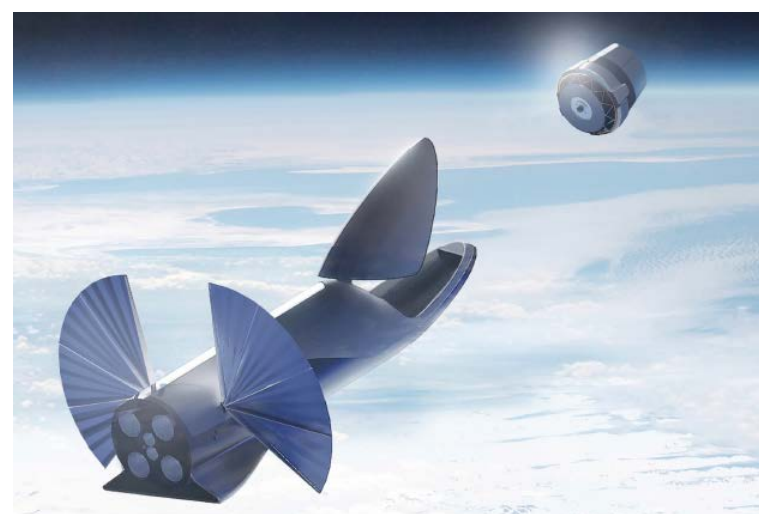

Figure 3: Artists impression of satellite payload release from BFS' open payload bay in LEO [3]

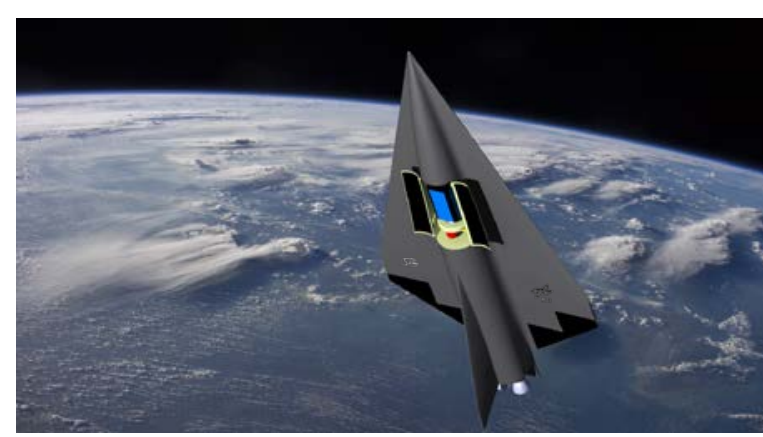

Figure 4: Artists impression of satellite payload release from SpaceLiner 7 Orbiter's open payload bay in LEO

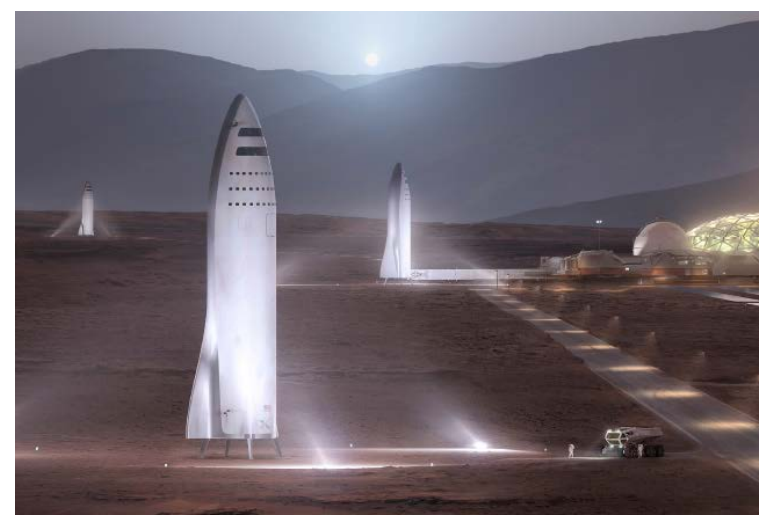

Figure 5: Artists impression of BFS 2017 at futuristic Martian spaceport [3]

\section{CONCEPTS CHARACTERISTICS}

This section gives an overview on the development history and summarizes the main technical characteristics based on previously published data. A more indepth analysis and comparison is presented in the following section 3 .

\subsection{BFR}

First proposed in 2017 by Elon Musk in a presentation to the public at the IAC in Adelaide [1], this very large fully reusable launch vehicle has been described as a technically more realistic type compared to the ITS proposed in 2016 at the IAC in Guadalajara, Mexico [12]. Significantly smaller than the interplanetary transport system (ITS), 4400 t GLOM vs. 10500 t, BFR would still be larger than any launcher built to date. 
The baseline architecture of BFR is a classical two stage configuration in tandem arrangement as shown in Figure 6 in the 2017 lay-out. Total length of the vehicle is announced at $106 \mathrm{~m}$ and the main body diameter is about 9 meters. Geometric data of the stages are listed in Table 1 and Table 2. The booster is lifted by 31 Raptor engines (see section 3.1.3) that produce a thrust of about 5400 tons, lifting the 4400 ton vehicle straight up [1]. The propellant combination is planned as LOX-LCH4 in both stages at subcooled conditions.

\subsection{SpaceLiner}

First proposed in 2005 [4], the SpaceLiner is under constant development. The European Union's $7^{\text {th }}$ Research Framework Programme has supported several important aspects of multidisciplinary and multinational cooperation in the projects FAST20XX, CHATT, HIKARI, and HYPMOCES [23]. In the EU's Horizon 2020 program a new project FALCon will be funded which addresses an advanced return mode of the reusable booster stage [11].

At the end of 2012 with conclusion of FAST20XX the SpaceLiner 7 reached a consolidated technical status. Another important milestone has been achieved in 2016 with the successful completion of the Mission Requirements Review (MRR) which allows the concept to mature from research to structured development [27].

The parallel arrangement of the two reusable vehicles at lift-off is presented in Figure 7: a large unmanned booster stage and a passenger or orbital upper stage. All 11 SLME engines (see section 3.2.3) are operating right from lift-off, 9 on the booster and 2 on the upper stage which is fed by propellant crossfeed in the mated section of the flight. External shapes of passenger and orbital configuration with satellite payload are almost identical. This approach intends enabling dramatic savings on development cost and moreover by manufacturing the vehicles on the same production line, also significantly lower hardware cost than would result for a dedicated new lay-out [27].

The internal arrangement of the upper stage is adapted to the specific mission with the forward passenger cabin replaced by a central cargo bay and adequately placed LOX-tank (Figure 7). The main dimensions of the 7-3 booster configuration are listed in Table 3 while major geometry data of the SpaceLiner 7-3 passenger or orbiter stage are summarized in Table 4.

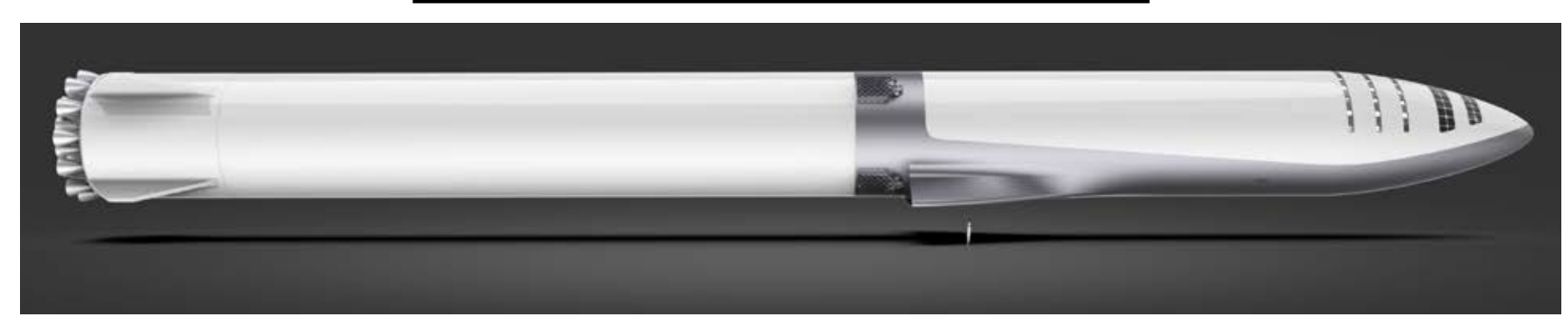

Figure 6: Drawing of BFR launch configuration with passenger stage on the right and booster stage on the left [3]

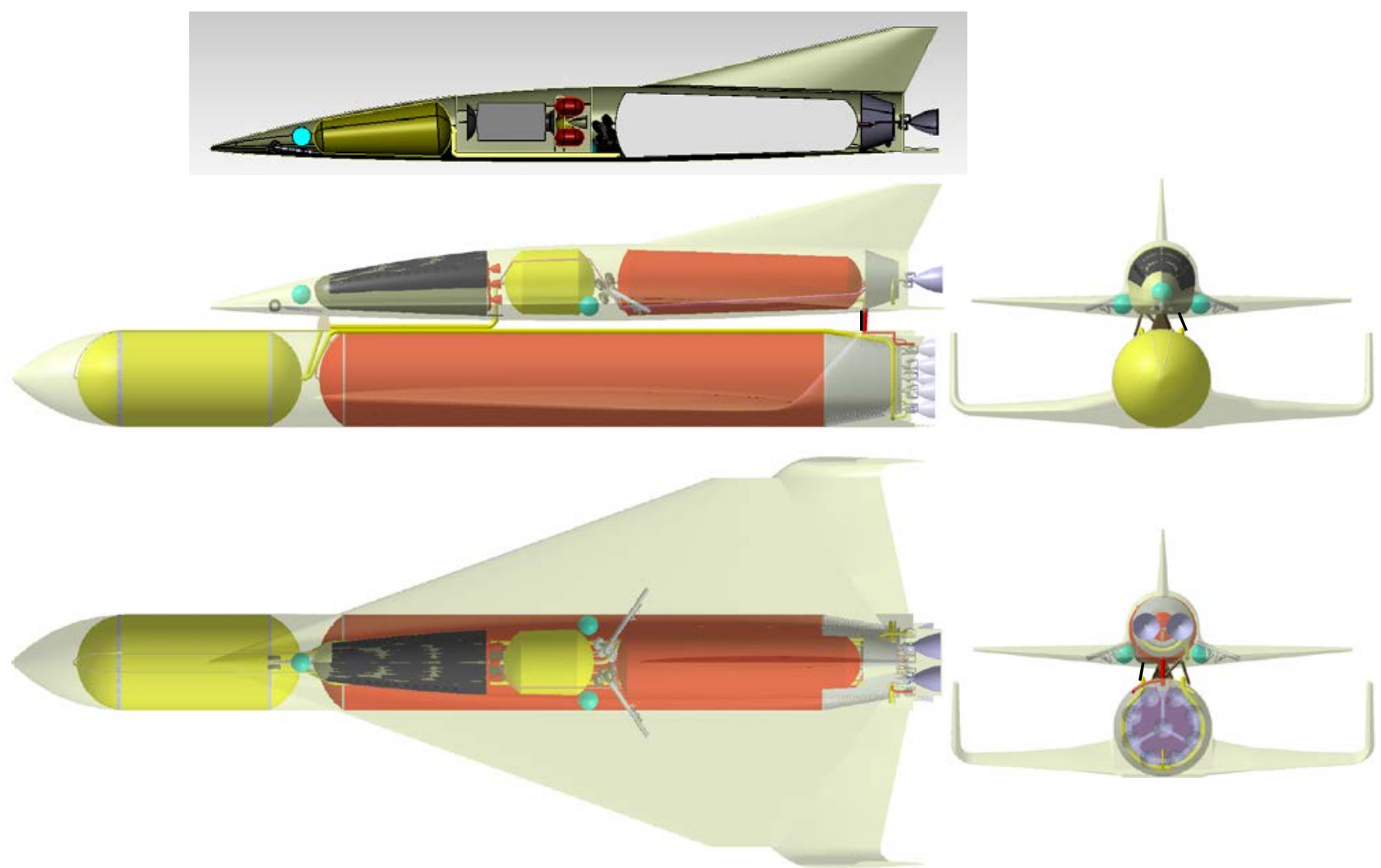

Figure 7: Sketch of SpaceLiner 7 launch configuration with passenger stage (SLP) with its booster stage at bottom position and orbital stage of SLO in insert at top 
Table 1: Geometrical data of BFR booster stage

\begin{tabular}{|c|c|c|c|c|c|c|}
\hline length [m] & $\begin{array}{c}\text { span incl. fins } \\
{[\mathrm{m}]}\end{array}$ & height [m] & $\begin{array}{c}\text { fuselage } \\
\text { diameter [m] }\end{array}$ & $\begin{array}{c}\text { wing leading } \\
\text { edge angles } \\
{[\mathrm{deg}]}\end{array}$ & $\begin{array}{c}\text { wing pitch } \\
\text { angle [deg] }\end{array}$ & $\begin{array}{c}\text { wing dihedral } \\
\text { angle [deg] }\end{array}$ \\
\hline 58 & $\approx 11$ & 9 & 9 & - & - & - \\
\hline
\end{tabular}

Table 2: Geometrical data of BFR orbiter and passenger stage (BFS)

\begin{tabular}{|c|c|c|c|c|c|c|}
\hline length [m] & span [m] & height [m] & $\begin{array}{c}\text { fuselage } \\
\text { diameter [m] }\end{array}$ & $\begin{array}{c}\text { wing leading } \\
\text { edge angle } \\
\text { [deg] }\end{array}$ & $\begin{array}{c}\text { wing pitch } \\
\text { angle [deg] }\end{array}$ & $\begin{array}{c}\text { wing dihedral } \\
\text { angle [deg] }\end{array}$ \\
\hline 48 & $\approx 14$ & 9 & 9 & $\approx 64$ & $\approx 0$ & $\approx-15$ \\
\hline
\end{tabular}

Table 3: Geometrical data of SpaceLiner 7-3 booster stage

\begin{tabular}{|c|c|c|c|c|c|c|}
\hline length [m] & span [m] & height [m] & $\begin{array}{c}\text { fuselage } \\
\text { diameter [m] }\end{array}$ & $\begin{array}{c}\text { wing leading } \\
\text { edge angles } \\
\text { [deg] }\end{array}$ & $\begin{array}{c}\text { wing pitch } \\
\text { angle [deg] }\end{array}$ & $\begin{array}{c}\text { wing dihedral } \\
\text { angle [deg] }\end{array}$ \\
\hline 82.3 & 36.0 & 8.7 & 8.6 & $82 / 61 / 43$ & 3.5 & 0 \\
\hline
\end{tabular}

Table 4: Geometrical data of SpaceLiner 7 orbiter and passenger stage

\begin{tabular}{|c|c|c|c|c|c|c|}
\hline length [m] & span [m] & height [m] & $\begin{array}{c}\text { max. fuselage } \\
\text { diameter [m] }\end{array}$ & $\begin{array}{c}\text { wing leading } \\
\text { edge angle } \\
\text { [deg] }\end{array}$ & $\begin{array}{c}\text { wing pitch } \\
\text { angle [deg] }\end{array}$ & $\begin{array}{c}\text { wing dihedral } \\
\text { angle [deg] }\end{array}$ \\
\hline 65.6 & 33.0 & 12.1 & 6.4 & 70 & 0.4 & 2.65 \\
\hline
\end{tabular}

Total dry mass of the SpaceLiner 7 launch configuration is estimated at $301 \mathrm{Mg}$ (satellite version) and $327 \mathrm{Mg}$ (passenger version) with a total propellant loading of $1467 \mathrm{Mg}$ or $1502 \mathrm{Mg}$. The resulting GLOWs are 1807 $\mathrm{Mg}$ (satellite version) and $1832 \mathrm{Mg}$ (passenger version) either incl. passengers or payload and expendable upper stage.

\section{CONCEPTS DESIGN ANALYSES}

\section{$3.1 \quad$ BFR 2017}

Recently, some technical updates of the BFR launcher have been announced. The analyses described in this section are all based on the configuration of 2017 [1]

\subsubsection{Reusable booster stage}

Available information on the BFR's reusable booster stage is limited to the stage's overall dimensions in length and diameter (Table 1). The tank lay-out as well as the required volume for thrustframe and engine installation is unknown as no figures of the internal arrangement of the first stage have been published by SpaceX. Thus to reach a better understanding of the BFR-configuration, DLR performed some reengineering work to allow a more precise, however, still preliminary estimation of propellant loading and major component's sizes.

An integral tank with common bulkhead allows for maximum propellant loading and has been selected as the baseline of the stage's remodeling. The propellant loading of the booster and the passenger stage were determined based on the overall dimensions of the BFR. Both LOX and methane are assumed to be sub-cooled (at fluid temperatures below normal boiling point) as SpaceX gained already operational experience with this technology in the Falcon 9. While Elon Musk is mentioning "deep cryo" cooled propellants [1], he is not specific on the average target fluid temperature inside the tanks. As the storage temperatures are unknown, the lowest possible temperatures very close to the respective freezing points were assumed in the DLR simulation to check on the maximum amount of propellant potentially to be loaded into the tanks. Tank mixture ratio is set to the Raptor engine mixture ratio which is sufficiently accurate for an initial assumption. A sketch of the booster stage's tank system generated with the DLR tool pmp is presented in Figure 8 and conditions of the loaded propellants are found in Table 5.

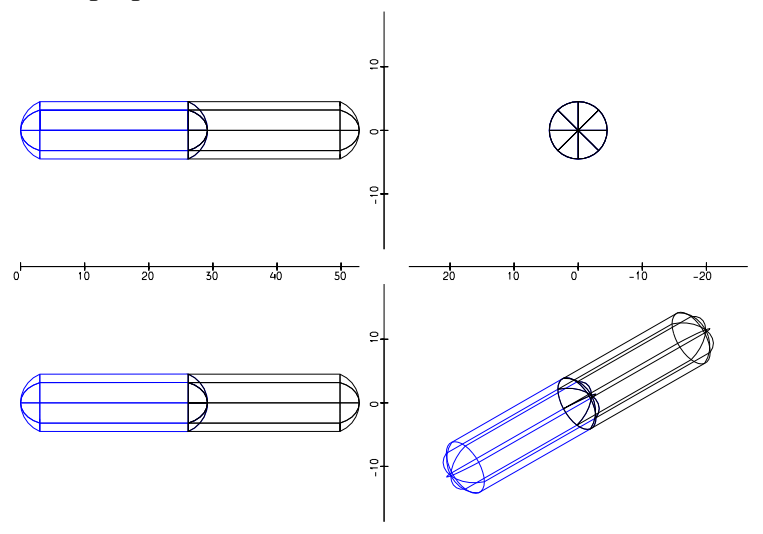

Figure 8: Sketch of the BFR booster stage tanks as modeled by DLR

Table 5: Estimated propellant conditions in the BFR booster stage

\begin{tabular}{|l|c|c|c|c|}
\hline & & total & LOX & LCH4 \\
\hline mixture ratio & - & 3.6 & & \\
\hline temperature & $\mathrm{K}$ & - & 54.5 & 91.0 \\
\hline density & $\mathrm{kg} / \mathrm{m}^{3}$ & & 1306 & 452 \\
\hline ullage pressure & $\mathrm{bar}$ & & 1.0 & 1.0 \\
\hline volume & $\mathrm{m}^{3}$ & & 1722 & 1452 \\
\hline mass & $\mathrm{t}$ & 2816 & 2204 & 612 \\
\hline height & $\mathrm{m}$ & 52.5 & & \\
\hline
\end{tabular}

Note that both fluid temperatures are assumed to be very low, close to their freezing points to achieve maximum 
density. Ullage pressure is assumed at 1.0 bar ambient conditions for the tank volume determination, reflecting practical filling operations. An increased pressure would have a minor impact on the fluids' density increase. The total tank length calculated by DLR is $52.5 \mathrm{~m}$ which leaves not more than $5.5 \mathrm{~m}$ for the integration of all 31 Raptor engines and their feeding lines. Details of such potential propulsion system integration have not been checked by DLR but could become challenging. Actually, a slight additional length compared to the tanks would result from the interstage connector in the stage front which further reduces the volume available for the main engine integration.

In conclusion, the DLR assumptions on the tank size are already quite ambitious and therefore it's unlikely that more than 2816 tons would fit inside the BFR's first stage. This value is already impressing, going well beyond what has ever been built in rocket history.

\subsubsection{Reusable upper stage}

Significantly more information is available on the layout of the upper stage which is a key-element for the multiple missions to be served by BFR. This stage is also called ship or BFS. The BFS should be capable of satellite transport to orbit, as a tanker for refilling transfer stages, as an interplanetary space ship, and as a passenger transport for the "Earth-to-Earth"-application. While the internal design is probably much different for the various missions, the external shape of BFS is likely similar.

Figure 9 shows the BFS geometry with an ogival nose section, cylindrical fuselage and a relatively small delta wing inclined that the lower side builds a flat surface with the fuselage. The chord thickness at the root is high and the airfoil is wedge-like without sharp trailing edge. This feature indicates that the wing is not intended to be used in low-speed and subsonic flight.

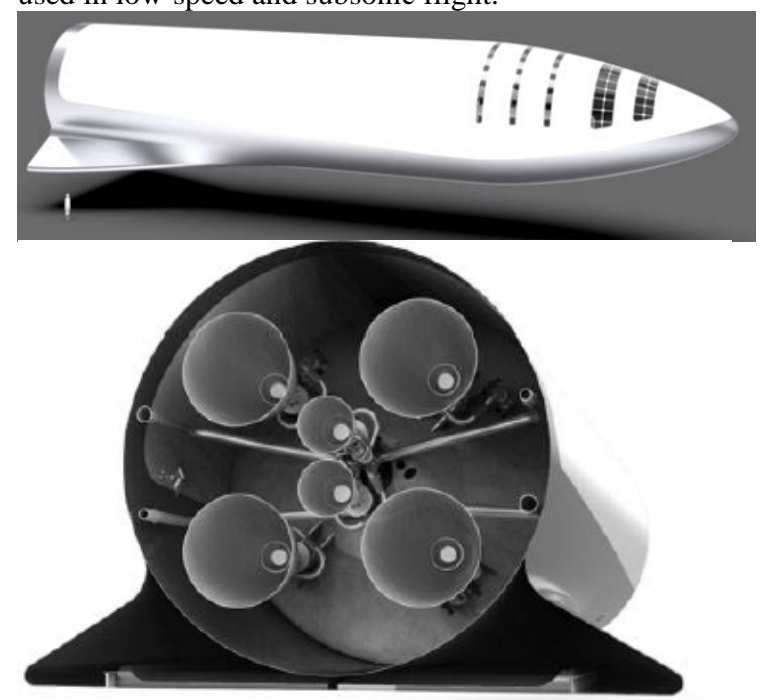

Figure 9: Drawings of BFR passenger stage or BFS in side and aft view $[1,3]$

However, in the hypersonic flow conditions of the atmospheric reentry such a wing is quite efficient. The maximum achievable L/D ratio of the BFS might be in the range from 1.35 up to slightly above 2 which would be quite good considering the relatively small size of the wing (Figure 10). Note that these data are for an untrimmed flight configuration as the dimensions of the BFS trimming devices are unknown. According to [1] the delta wing also includes a split flap for pitch and roll control, which should allow "to control the pitch angle for a wide range of payloads in the forward nose and a wide range of atmospheric densities".

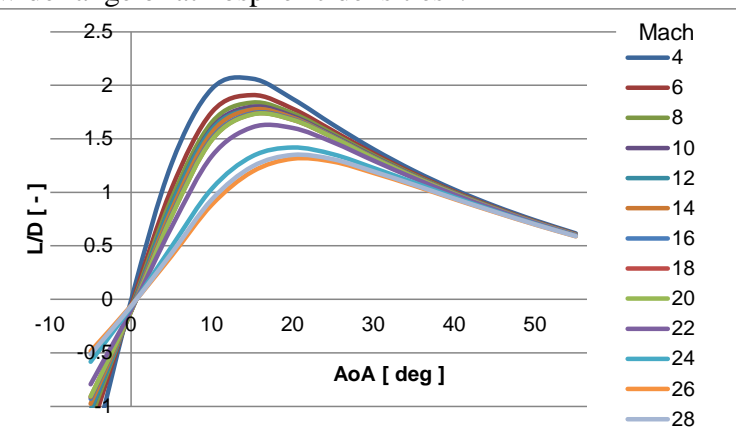

Figure 10: Calculated aerodynamic efficiency of BFS in hypersonic flight (untrimmed)

The ship is 48 meters in length, having the engine section in the rear, the propellant tanks in the middle and a large payload bay in the front (see Figure 11). The ship engine section consists of four vacuum Raptor engines with large nozzle expansion ratios and two sealevel engines (Figure 9). All six engines are capable of gimbaling. [1] The cargo area has a pressurized volume of 825 cubic meters [1].

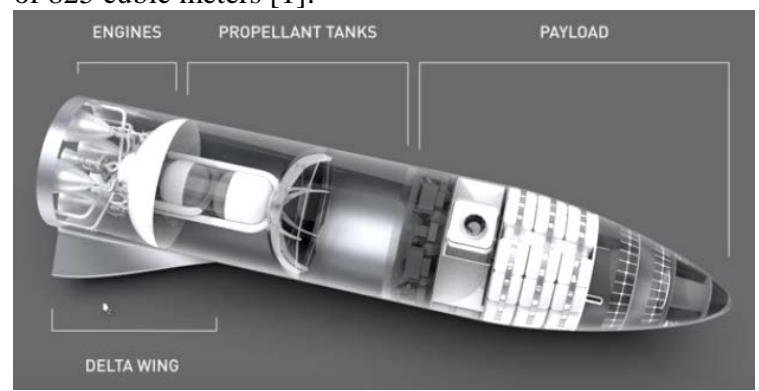

Figure 11: Drawing of BFS in passenger configuration showing internal sections [3]

The passenger stage contains two main tanks and two header tanks (Figure 12). The main tanks contain the propellant for the ascent, the header tanks the propellant for the return to Earth. [1] The header tanks are fully immersed in the main LCH4-tank.

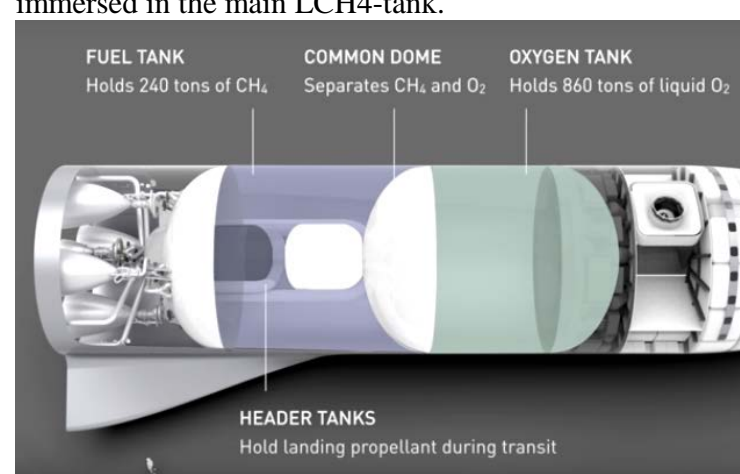

Figure 12: Drawing of BFS highlighting tank and engine sections [3]

Musk explains the need for the header tanks saying "when you come in for landing, your orientation may change quite significantly, but you cannot have the propellant just sloshing around all over in the main tanks" [1] and the header tanks allow feeding the main 
engines with precision. A similar situation exists in the booster stage when performing its RTLS maneuver, however, nothing is known about any header tanks or other devices to be included in the lower stage.

According to reference 1 the BFS stage is expected to carry 240 tons of methane and 860 tons of oxygen. Based on this information and using Figure 12 DLR calculated the BFS tank system. As visible in Figure 13 and Table 6, the intended propellant loading of 1100 tons fits in the available length. While LCH4 is again subcooled close to its freezing point, the temperature of subcooled LOX could be kept above $66 \mathrm{~K}$ in the BFS.

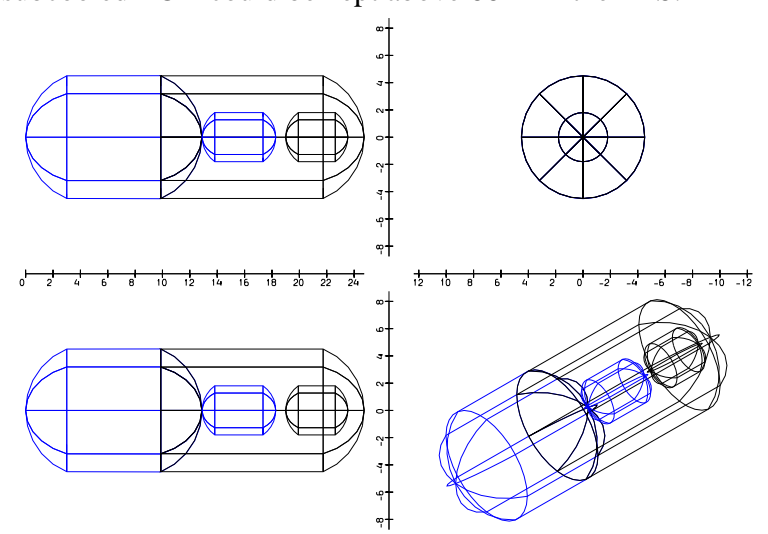

Figure 13: Sketch of the BFR passenger stage tanks as modeled by DLR

Table 6: Estimated propellant conditions in the BFR's passenger stage

\begin{tabular}{|l|c|c|c|c|}
\hline & & total & LOX & LCH4 \\
\hline mixture ratio & - & 3.6 & & \\
\hline temperature & $\mathrm{K}$ & & 66.7 & 91.0 \\
\hline density & $\mathrm{kg} / \mathrm{m}^{3}$ & & 1252 & 452 \\
\hline pressure & $\mathrm{bar}$ & & 1.0 & 1.0 \\
\hline volume Main & $\mathrm{m}^{3}$ & & 665 & 725 \\
\hline volume Header & $\mathrm{m}^{3}$ & & 47 & 36 \\
\hline mass & $\mathrm{t}$ & 1104 & 864 & 240 \\
\hline height & $\mathrm{m}$ & 24.4 & & \\
\hline
\end{tabular}

\subsubsection{Main propulsion system}

The SpaceX’ Raptor engine is designed as closed staged combustion cycle using LOX - methane as propellants. This is a major technological shift from today's Merlin 1D powering the Falcon 9 launcher which is of open gas generator cycle and is burning the LOX-RP1 propellant combination. A Full-Flow Staged Combustion Cycle (FFSC) with a fuel-rich preburner gas turbine driving the LCH4-pump and an oxidizer-rich preburner gas turbine driving the LOX-pump is significantly more demanding while at the same time offering better performance.

The Raptor has been promoted by Elon Musk, "CEO and Lead Designer, SpaceX” $[1,12]$. Originally Raptor was foreseen as an ultra-high performance LOX-LCH4 engine with $3290 \mathrm{kN}$ of vacuum thrust and $30 \mathrm{MPa}$ chamber pressure (Figure 14). Meanwhile, technical requirements of the first generation Raptor have been reduced. In his 2017 IAC speech Musk announced a first generation engine operating at $25 \mathrm{MPa}$ chamber pressure and thrust level of $1700 \mathrm{kN}$ to be included in the fully reusable "BFR" TSTO launcher [1].

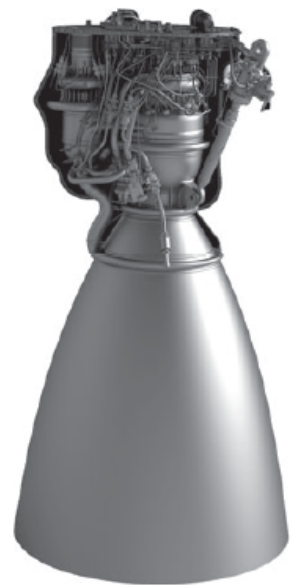

Figure 14: CAD-model of SpaceX' Raptor engine in $3290 \mathrm{kN}$ variant [12]

In September 2017 SpaceX had 1200 seconds of Raptor firing across 42 main engine tests for as long as 100 seconds [1].

Results on a first DLR recalculation of the smaller Raptor assuming again nozzle expansion ratios of 40 and 200 as for the earlier version have been published in [13]. However, in [3] SpaceX explicitly mentions the exit diameters of Raptor both for the sea-level and the vacuum optimized variants to be at $1.3 \mathrm{~m}$ and $2.4 \mathrm{~m}$. Assuming a chamber pressure of $25 \mathrm{MPa}$ and thrust levels $1700 \mathrm{kN}(\mathrm{s} / \mathrm{l})$ and $1900 \mathrm{kN}$ (vac) it rapidly turns out that the nozzle area ratios have been reduced. The estimation of the actual expansion ratios is straightforward using the DLR tool ncc and delivers approximately 35 for the booster variant and 115 for the BFS.

Both estimated nozzle expansion ratios are reasonable for the intended application and are used in the numerical engine analyses. The Raptor performance calculations have been executed by simulation of steadystate operation using the DLR-tool lrp 1.1 and the commercially available tool RPA 2.3. The engine mixture ratio is not known and has been selected very close to the optimum Isp achievable for $25 \mathrm{MPa}$ chamber pressure and the nozzle expansion ratios.

Table 7 provides for both Raptor variants a comparison between DLR calculation and published data from [1, 3 ]. Overall, the agreement is quite good with only minor reduction in vacuum Isp compared to what has been announced. This small deviation is not at all a proof that the engine performance of SpaceX is unlikely of being achieved. However, the challenging design targets of Raptor are underscored. Pump discharge pressures of Raptor might be in the ambitious range of 48 to 52.5 MPa assuming highly efficient turbines and pumps.

Reference 3 confirms the large throttling range requirement of Raptor from $100 \%$ down to $20 \%$ nominal thrust level. The low-level is critical to potential flow-separation in the nozzle at sea-level conditions. However, it seems unlikely that $20 \%$ throttle setting is necessary for landing on Earth. This low value might be required for controlled touch-down under Moon gravity. 
The estimated engine $\mathrm{T}_{\mathrm{vac}} / \mathrm{W}$ could reach beyond 94 . Musk claims in [1] "the Raptor engine will be the highest thrust-to-weight engine, we believe, of any engine of any kind ever made" which is not confirmed by the DLR assessment. Again the DLR calculation is not challenging the credibility of this statement but rather serves as an indication of the technical challenge. Any detailed information for comparison to calculated mass and internal pressure is not yet available in publications.

\subsubsection{System masses}

As already described in section 3.1.1, limited data are published for the BFR-booster stage. This applies also for all stage masses. In contrary to this situation Musk refers in [1] to the upper stage: "Dry mass is expected to be about 85 tons. Technically, our design says 75 tons but inevitably there will be mass growth. The ship will contain 1100 tons of propellant with an ascent design of 150 tons and return mass of 50 tons.”

DLR performed an early simplified mass assessment of both BFR stages based on basic geometry and load data using the internal tool stsm making use of empirically based mass relationships for some major components. Data are from legacy launch vehicles, mostly ELV including the Saturn V. Table 8 through Table 10 summarize obtained stage masses. Dry mass of the upper stage is preliminarily estimated at 109 tons including more than $9000 \mathrm{~kg}$ for the passenger cabin which is above the 85 tons mentioned in [1]. SpaceX intends introducing highly advanced, extremely light weight structures which might not be reflected in the standard mass estimation approach. Note that total GLOW of the BFR2017 in Table 10 is 4270 tons which is below the 4400 tons declared in [1, 3]. A reduced structural weight would increase payload mass but as propellant loading of the stages is restricted by the available volume, approaching the 4400 tons in combination with the 150 ton payload target could become difficult.

The calculated structural indices are at 8.3\% (Table 8) and $9.9 \%$ (Table 9) which on a first look might seem less ambitious than the already flying Falcon 9. However, the lower density of methane compared to RP1 as well as requirements for a fully reusable manned stage should be taken into account.

Table 7: BFR Main Engine (Raptor) technical data

\begin{tabular}{|l|c|c|c|c|}
\hline & \multicolumn{2}{|c|}{ Booster } & \multicolumn{2}{c|}{ Upper Stage (BFS) } \\
\hline & DLR calc. & {$[1,3]$} & DLR calc. & {$[1,3]$} \\
\hline Mixture ratio [-] & 3.6 & & 3.6 & \\
\hline Chamber pressure [MPa] & 25 & 25 & 25 & 25 \\
\hline Mass flow per engine [kg/s] & 530.5 & & 530.5 & \\
\hline Expansion ratio [-] & 35 & & 115 & \\
\hline Specific impulse in vacuum [s] & 354 & 356 & 374 & 375 \\
\hline Specific impulse at sea level [s] & 326.5 & 330 & 285 & \\
\hline Thrust in vacuum per engine [kN] & 1841 & & 1947 & 1900 \\
\hline Thrust at sea level per engine [kN] & 1700 & 1700 & 1484 & \\
\hline
\end{tabular}

Table 8: DLR estimated mass data of BFR booster stage

\begin{tabular}{|c|c|c|c|}
\hline Total dry [Mg] & $\begin{array}{c}\text { Total } \\
\text { propellant } \\
\text { loading }[\mathrm{Mg}]\end{array}$ & $\begin{array}{c}\text { Structural } \\
\text { Index SI [-] }\end{array}$ & GLOW [Mg] \\
\hline 233.2 & 2800 & 0.083 & 3033 \\
\hline
\end{tabular}

Table 9: DLR estimated mass data of BFR passenger stage

\begin{tabular}{|c|c|c|c|}
\hline Total dry $[\mathrm{Mg}]$ & $\begin{array}{c}\text { Total } \\
\text { propellant } \\
\text { loading }[\mathrm{Mg}]\end{array}$ & $\begin{array}{c}\text { Structural } \\
\text { Index [-] }\end{array}$ & $\begin{array}{c}\text { GLOW incl. } \\
\text { passengers \& } \\
\text { payload [Mg] }\end{array}$ \\
\hline 109.2 & 1100 & 0.099 & 1209 \\
\hline
\end{tabular}

Table 10: DLR estimated mass data of BFR passenger launch configuration

\begin{tabular}{|c|c|c|}
\hline Total dry [Mg] & $\begin{array}{c}\text { Total } \\
\text { propellant } \\
\text { loading [Mg] }\end{array}$ & $\begin{array}{c}\text { GLOW incl. } \\
\text { passengers \& } \\
\text { payload [Mg] }\end{array}$ \\
\hline 342.4 & 3900 & 4270 \\
\hline
\end{tabular}

\subsection{SpaceLiner}

\subsubsection{Reusable booster stage}

The SpaceLiner 7 booster geometry is relatively conventional with two large integral tanks with separate bulkheads for LOX and LH2 which resembles the Space Shuttle External tank lay-out (Figure 15). The major additions to the ET are an ogive nose for aerodynamic reasons and for housing subsystems, the propulsion system, and the wing structure with landing gear.

The overall size of the booster is reaching significant dimensions of more than $80 \mathrm{~m}$ in length. The current configuration of the booster has been defined based on extensive analyses of the propellant crossfeed system $[13,21]$, pre-design of major structural parts like tanks, 
intertank and the thrust frame. Further, the size of the body flap and the geometry of the large wing were optimized. Major geometrical data of this configuration 7-3 are listed in Table 3.

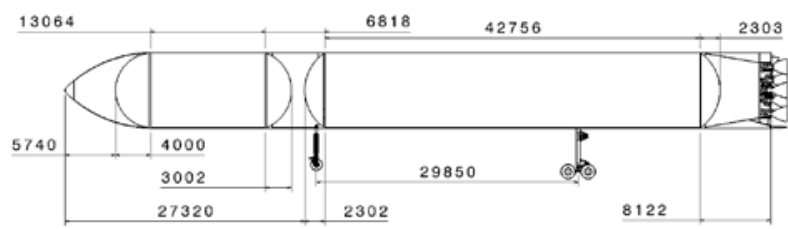

Figure 15: Sketch of SpaceLiner 7 booster stage

\subsubsection{Reusable upper stage}

The SpaceLiner7 aerodynamic shape is a result of a trade-off between the optima of three reference trajectory points and showed considerable improvements in glide ratio and heat loads compared with previous designs and pointed out the clear advantages of a single delta wing [14]. Major geometry data of the SpaceLiner 7-3 passenger and orbiter stage are summarized in Table 4. The SpaceLiner passenger stage's shape is shown in Figure 16.

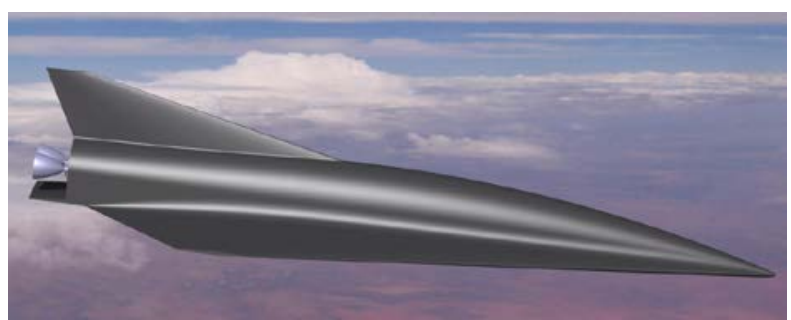

Figure 16: SpaceLiner 7-3 passenger stage

The passenger stage needs to be redesigned for its secondary role as an unmanned satellite launcher. The passenger cabin (see section 3.2.4 below!) is no longer needed and is to be replaced by a large internal payload bay.

Key geometrical constraints and requirements are set that the SpaceLiner 7 passenger stage's outer mold line and aerodynamic configuration including all flaps should be kept unchanged. The internal arrangement of the vehicle could be adapted; however, maximum commonality of internal components (e.g. structure, tanks, gear position, propulsion and feed system) to the passenger version is preferred because of cost reflections. Further, the payload bay should provide sufficient volume for the accommodation of a large satellite and its orbital transfer stage.

The stage's propellant loading has been reduced by 24 Mg to $190 \mathrm{Mg}$ with a smaller LOX-tank to allow for a payload bay length of $12.1 \mathrm{~m}$ and at least $4.75 \mathrm{~m}$ diameter. These dimensions are close to the Space Shuttle $(18.3 \mathrm{~m} \times 5.18 \mathrm{~m} \times 3.96 \mathrm{~m})$ and should accommodate even super-heavy GTO satellites of more than $8 \mathrm{~m}$ in length and their respective storable upper stage (Figure 17). Large doors open on the upper side to enable easy and fast release of the satellite payload in orbit as illustrated in Figure 4.

The orbiter stage mass has been estimated based on the SpaceLiner 7-3 passenger stage budget (see Table 12 on p. 10). Adaptations include the complete removal of all cabin related masses. Instead a mass provision for the payload bay and its mechanisms including doors, the mounting structure, and also a radiator system for onorbit heat-control is added. The resulting orbiter dry mass is about $102 \mathrm{Mg}$ and the budget is listed in Table 14.
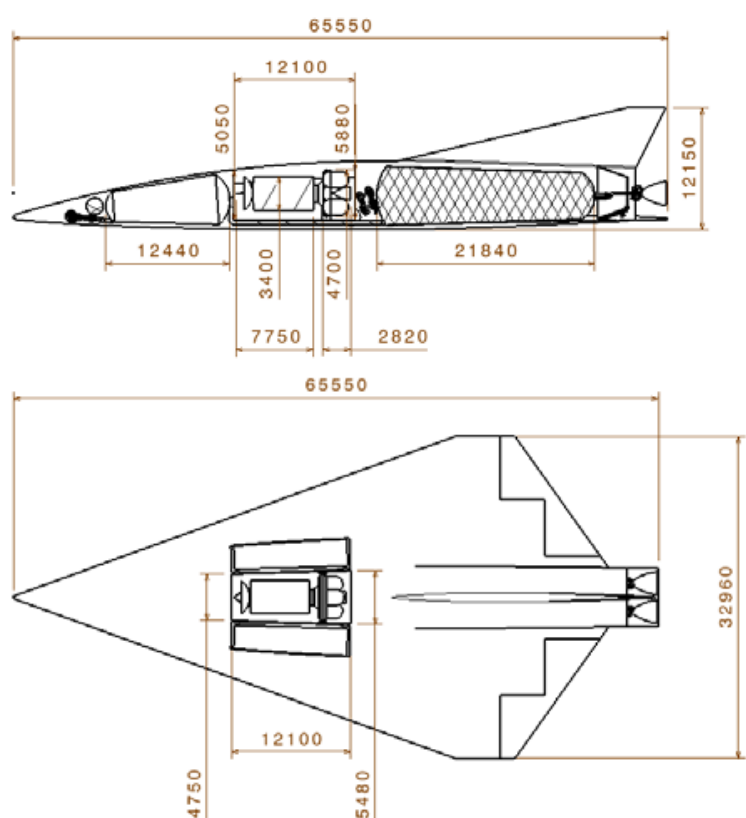

Figure 17: Sketch of SpaceLiner 7 as orbital space transportation with internal cargo bay for satellites

The aerodynamic trimming with the existing trailing edge flaps and the bodyflap has been preliminarily checked in numerical simulation under hypersonic flow conditions and is found feasible within the constraints of the present lay-out. This promising outcome is a result of the robust SpaceLiner design philosophy which is also taking into account off-nominal abort flights. The calculated maximum L/D is reduced approximately $15 \%$ by the significant flap deflections compared to the L/D achievable for the nominal passenger mission with almost no deflection. Pre-trimmed aerodynamic data sets have been generated and were used for reentry trajectory simulations of the orbiter.

\subsubsection{Main propulsion system}

Staged combustion cycle rocket engines with a moderate $16 \mathrm{MPa}$ chamber pressure have been selected as the baseline propulsion system right at the beginning of the project [4]. A Full-Flow Staged Combustion Cycle with a fuel-rich preburner gas turbine driving the LH2-pump and an oxidizer-rich preburner gas turbine driving the LOX-pump is also the preferred design solution for the SpaceLiner.

The expansion ratios of the booster and passenger stage/ orbiter engines are adapted to their respective optimums; while the mass flow, turbo-machinery, and combustion chamber are assumed to remain identical in the baseline configuration.

The SpaceLiner 7 has the requirement of vacuum thrust up to $2350 \mathrm{kN}$ and sea-level thrust of $2100 \mathrm{kN}$ for the booster engine and $2400 \mathrm{kN}, 2000 \mathrm{kN}$ respectively for the passenger stage. All these values are given at a mixture ratio of 6.5 with a nominal operational MR- 
range requirement from 6.5 to 5.5 . Table 11 gives an overview about major SLME engine operation data for the nominal MR-range as obtained by cycle analyses. The SpaceLiner's architecture of vertical take-off and horizontal landing and operational environment currently restricted to the Earth, allow for a much smaller throttling range than required for Raptor. The variation can be limited between approximately $82 \%$ to $108 \%$ of nominal thrust at MR=6.0. A smaller operational range could result in simplified engine lay-out and potentially in cost savings.

Table 11: SpaceLiner Main Engine (SLME) technical data [13, 20]

\begin{tabular}{|l|c|c|c|c|c|c|}
\hline & \multicolumn{3}{|c|}{ Booster } & \multicolumn{3}{c|}{ Passenger Stage } \\
\hline Mixture ratio [-] & 5.5 & 6.0 & 6.5 & 5.5 & 6.0 & 6.5 \\
\hline Chamber pressure [MPa] & 15.1 & 16.0 & 16.9 & 15.1 & 16.0 & 16.9 \\
\hline Mass flow per engine [kg/s] & 481 & 517 & 555 & 481 & 518 & 555 \\
\hline Expansion ratio [-] & 33 & 33 & 33 & 59 & 59 & 59 \\
\hline Specific impulse in vacuum [s] & 439 & 437 & 435 & 451 & 449 & 448 \\
\hline Specific impulse at sea level [s] & 387 & 389 & 390 & 357 & 363 & 367 \\
\hline Thrust in vacuum per engine [kN] & 2061 & 2206 & 2356 & 2116 & 2268 & 2425 \\
\hline Thrust at sea level per engine [kN] & 1817 & 1961 & 2111 & 1678 & 1830 & 1986 \\
\hline
\end{tabular}

The size of the SLME in the smaller booster configuration is a maximum diameter of $1800 \mathrm{~mm}$ and overall length of $2981 \mathrm{~mm}$. The larger passenger stage SLME has a maximum diameter of $2370 \mathrm{~mm}$ and overall length of $3893 \mathrm{~mm}$. A size comparison of the two variants and overall arrangement of the engine components is visible in Figure 18. All engines have a 2D TVC (thrust vector control) capability with gimbal mechanism which should be electro-mechanically actuated.

The engine masses are estimated at $3375 \mathrm{~kg}$ with the large nozzle for the passenger stage and at $3096 \mathrm{~kg}$ for the booster stage. These values are equivalent to vacuum $\mathrm{T} / \mathrm{W}$ at $\mathrm{MR}=6.0$ of 68.5 and 72.6 .

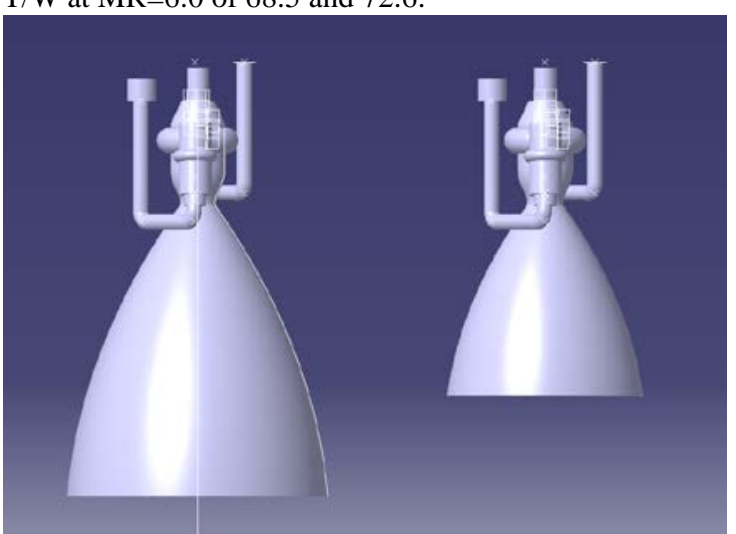

Figure 18: Size comparison of simplified CAD-shapes of SLME with $\varepsilon=59$ (left) and $\varepsilon=33$ (right)

\subsubsection{Cabin and rescue system}

The passenger cabin of the SpaceLiner has a double role. Providing first a comfortable pressurized travel compartment which allows for horizontal entrance of the passengers, the cabin in its second role serves as a reliable rescue system in case of catastrophic events. Thus, the primary requirements of the cabin are the possibility of being firmly attached late in the launch preparation process and fast and safely separated in case of an emergency.

The capsule is able to fly autonomously back to Earth's surface in all separation cases. The abort trajectories are primarily influenced by the mass of the capsule and the aerodynamic performance with the most important subsystems being the separation motors, the thermal protection system (TPS), and the structure. These three subsystems have been investigated and sized for function, performance, and mass [17, 25, 27, 28].

Overall length of the capsule without separation motors is $15.6 \mathrm{~m}$ and its maximum external height is $5.6 \mathrm{~m}$. The estimated masses are about 26.4 tons for the dry capsule (reference SpaceLiner 7-3), about $7600 \mathrm{~kg}$ for the passengers, crew and luggage, and $3400 \mathrm{~kg}$ for all propellants of separation motor, retro-rockets and RCS [28].

A fundamental requirement for the design of the rescue capsule is its integration in the front section of the passenger stage. The capsule should be separated as easily and quickly as possible. Therefore, it cannot be an integral part of the fuselage structure, however, its upper aft section is conformal with the SpaceLiner's fuselage while the lower side is fully protected by the fuselage bottom structure. The current requirement of capsule separation being feasible at any flight condition and attitude is highly challenging from a technical point of view. Analyses revealed some critical issues to be addressed in order to improve the safe functionality of the cabin rescue system. Alternative capsule integration concepts have been proposed and technically analyzed $[18,25]$. However, each of the explored design options is linked to severe challenges and drawbacks. Further investigations are ongoing to find a promising and reliable system [18].

A highly innovative investigation on design options to improve the capsules flight performance after separation has been performed in the European Commission funded FP7-project HYPMOCES aiming to investigate and develop the technologies in the area of control, structures, aerothermodynamics, mission and system aspects required to enable the use of morphing structures $[23,28]$.

\subsubsection{System masses}

Based on available subsystem sizing and empirical mass estimation relationships, the passenger stage mass is derived as listed in Table 13. The total fluid and propellant mass includes all ascent, residual, and RCS propellants and the water needed for the active leading edge cooling [5, 8, 19, 24, 27]. The stages’ MECO mass 
is approximately $151.1 \mathrm{Mg}$. The SpaceLiner 7-3's GLOW reaches about $1832 \mathrm{Mg}$ (Table 15) for the reference mission Australia - Europe while the TSTO is at $1807 \mathrm{Mg}$ (Table 16) still below that of the Space Shuttle STS of more than $2000 \mathrm{Mg}$.

The structural index of the SpaceLiner booster stage is $15.6 \%$, almost twice that of the BFR booster. The passenger stage with its capsule reaches even 55\% SI more than 5 times above the BFS. The difference is due to several reasons: the SpaceLiner stages with large wings, the propellant choice of low density hydrogen and the considerably lower overall propellant loading which usually has the general tendency of increased SI. The main driver, however, of SpaceLiner's higher structural index is linked to the intentionally robust design philosophy of the concept.

Table 12: Mass data of SpaceLiner 7-3 booster stage

\begin{tabular}{|c|c|c|c|c|c|c|}
\hline Structure $[\mathrm{Mg}]$ & $\begin{array}{c}\text { Propulsion } \\
{[\mathrm{Mg}]}\end{array}$ & $\begin{array}{c}\text { Subsystem } \\
{[\mathrm{Mg}]}\end{array}$ & TPS [Mg] & Total dry [Mg] & $\begin{array}{c}\text { Total } \\
\text { propellant } \\
\text { loading }[\mathrm{Mg}]\end{array}$ & GLOW [Mg] \\
\hline 123.5 & 36.9 & 18.9 & 19.1 & 198.4 & 1272 & 1467 \\
\hline
\end{tabular}

Table 13: Mass data of SpaceLiner 7-3 passenger stage

\begin{tabular}{|c|c|c|c|c|c|c|}
\hline Structure [Mg] & $\begin{array}{c}\text { Propulsion } \\
{[\mathrm{Mg}]}\end{array}$ & $\begin{array}{c}\text { Subsystems } \\
\text { including cabin } \\
{[\mathrm{Mg}]}\end{array}$ & TPS [Mg] & Total dry [Mg] & $\begin{array}{c}\text { Total fluid \& } \\
\text { propellant } \\
\text { loading [Mg] }\end{array}$ & $\begin{array}{c}\text { GLOW incl. } \\
\text { passengers \& } \\
\text { payload [Mg] }\end{array}$ \\
\hline 55.3 & 9.7 & 43.5 & 22.3 & 129 & 232.1 & 366 \\
\hline
\end{tabular}

Table 14: Mass data of SpaceLiner 7 Orbiter stage (GTO mission)

\begin{tabular}{|c|c|c|c|c|c|c|}
\hline Structure [Mg] & $\begin{array}{c}\text { Propulsion } \\
{[\mathrm{Mg}]}\end{array}$ & $\begin{array}{c}\text { Subsystems } \\
{[\mathrm{Mg}]}\end{array}$ & TPS [Mg] & Total dry [Mg] & $\begin{array}{c}\text { Total fluid \& } \\
\text { propellant } \\
\text { loading [Mg] }\end{array}$ & $\begin{array}{c}\text { GLOW incl. } \\
\text { kick-stage \& } \\
\text { payload [Mg] }\end{array}$ \\
\hline 60.1 & 9.9 & 9.8 & 22.3 & 102 & 207 & 309.1 \\
\hline
\end{tabular}

Table 15: Mass data of SpaceLiner 7-3 passenger launch configuration

\begin{tabular}{|c|c|c|}
\hline Total dry $[\mathrm{Mg}]$ & $\begin{array}{c}\text { Total } \\
\text { propellant } \\
\text { loading }[\mathrm{Mg}]\end{array}$ & $\begin{array}{c}\text { GLOW incl. } \\
\text { passengers \& } \\
\text { payload [Mg] }\end{array}$ \\
\hline 327.4 & 1502 & 1832.2 \\
\hline
\end{tabular}

Table 16: Mass data of SpaceLiner 7-3 TSTO launch configuration

\begin{tabular}{|c|c|c|}
\hline Total dry [Mg] & $\begin{array}{c}\text { Total } \\
\text { propellant } \\
\text { loading [Mg] }\end{array}$ & $\begin{array}{c}\text { GLOW incl. } \\
\text { kick-stage \& } \\
\text { payload [Mg] }\end{array}$ \\
\hline 300.6 & 1467 & 1807 \\
\hline
\end{tabular}

\section{TRAJECTORIES FEASABILITY AND PERFORMANCE ASSESSMENT}

Multiple mission launch vehicles are intentionally designed for a wide range of missions. This could reach up to interplanetary travels. This section has its focus on two typical target operations both for BFR and for the SpaceLiner: satellite transport to Earth orbit and ultrafast intercontinental passenger flight.

\subsection{Orbital transport mission}

\subsubsection{BFR}

In reference 1 the BFR target payload performance is described: "in fully reusable configuration, without any orbital refueling, we expect to have a payload capability of 150 tons to low Earth orbit”. Although the LEO parameters are not specified, the easterly ascent from LC39 into a target orbit of $250 \mathrm{~km} \mathrm{x} 300 \mathrm{~km}$ is a reasonable first assumption.

Two options exist for the recovery of the BFR booster stage which both are already operational with SpaceX' Falcon 9: the return to launch site (RTLS) and the down-range landing (DRL) on a sea-going platform or ship. A systematic assessment of RLV return options is provided in [26] and similar studies are continuing in DLR. Both, RTLS and DRL, have been considered for the simulation of a potential BFR LEO mission.

Pushing reusable stages back to their launch site using the rocket engines (RTLS) requires a significant amount of propellant to perform this maneuver. Thus, ascent stage mass ratio for acceleration is reduced which has a major impact on payload performance. [26] In case of the BFR LEO mission, a DLR trajectory optimization reveals that approximately 220 tons propellant $(7.86 \%$ of total loading) would be required for return and landing of the booster.

The downrange landing approach of the reusable first stage is much more efficient, however, needs additional infrastructure [26]. Regarding the same LEO-mission but using DRL, the booster stage requires approximately $84.5 \mathrm{t}$ of propellant.

A few parameters from the DLR simulated ascent trajectory of BFR with best performance are shown in Figure 19. Separation of the booster stage occurs at approximately $2 \mathrm{~km} / \mathrm{s}$ in $83 \mathrm{~km}$ altitude. The upper stage is performing the rest of the mission and executes its 
MECO less than 10 minutes after lift-off. Maximum acceleration is expected to remain below $4.5 \mathrm{~g}$.
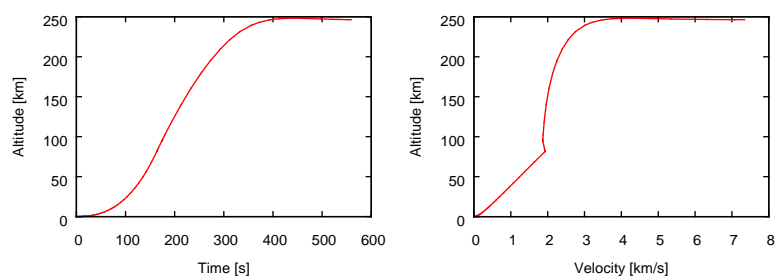

Figure 19: DLR simulation of BFR ascent into LEO

The corresponding trajectory optimization of a downrange landing is presented in Figure 20. A reentry burn to limit the atmospheric loads and a final landing burn is required. Despite the propulsive maneuvers, mechanical loads on the stage can reach up to $8 \mathrm{~g}$ and a peak dynamic pressure of close to $140 \mathrm{kPa}$. The obtained characteristics resemble those of the Falcon 9 trajectories. The only major difference is with the significantly larger size of the stage.
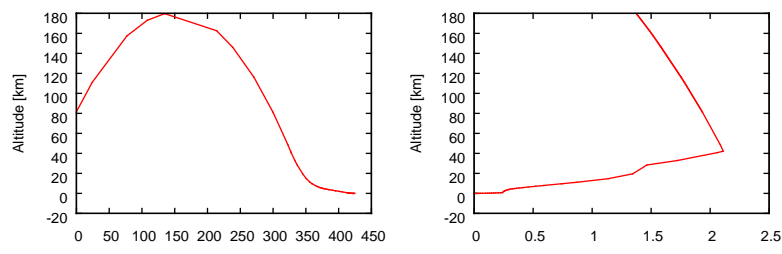
Time $[s]$
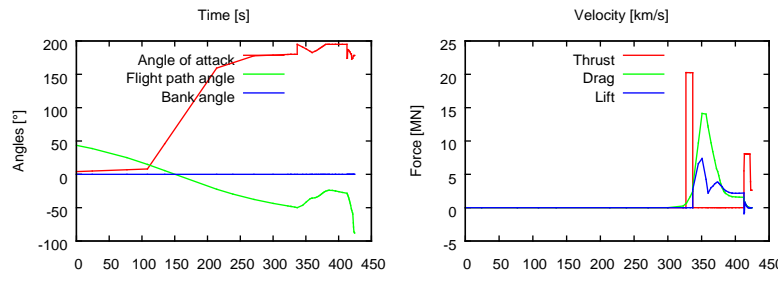

Time $[s]$

Figure 20: DLR simulation of BFR booster postMECO flight up to final downrange landing

The achievable payload to orbit is strongly depending on the stage masses. Using the DLR estimated masses from Table 8 and Table 9 and assuming RTLS, the BFR payload could reach around 40 tons. In case of booster stage DRL, payload performance into LEO is found around 67 t. Both values fall short of the BFR target payload capability of 150 tons "in fully reusable configuration" as mentioned in reference 1 .

Discarding the DLR mass estimation of BFS and instead assuming 85 tons dry mass as in [1] would add another 24 tons reaching a capability of approximately $91 \mathrm{t}$. Further, if the booster stage mass could be significantly reduced down to $5.9 \%$ SI (challenging for an $\mathrm{LCH} 4-$ LOX-stage to be designed for numerous reuses), the separated payload in LEO could increase beyond 100 tons. Such launch capability is highly impressive because the value is far beyond what has ever been achieved by a reusable system. As the first stage dry mass has a limited impact on launcher performance, even the most extreme SI-assumptions would not support 150 tons payload mas of the BFR2017 in a 250 $\mathrm{km} \times 300 \mathrm{~km}, 28^{\circ} \mathrm{LEO}$. One option to further increase payload capacity could be the release of cargo in an even lower transfer orbit while the BFS falls back to Earth. This approach is proposed for the SpaceLiner (see following section 4.1.2) but requires an additional transfer stage.

\subsubsection{SpaceLiner}

Launch of the SpaceLiner 7 TSTO has been simulated from the Kourou space center into a low $30 \mathrm{~km} \times 250$ $\mathrm{km}$ transfer orbit (Figure 21). Actually, this trajectory allows at least for the GTO mission that the orbiter stage becomes a once-around-Earth-vehicle capable of reaching its own launch site after a single circle around the planet. As a consequence, the achievable payload mass increases and overall complexity is reduced; e.g. an active deorbiting is not needed. Trajectory optimizations show that the orbiter is able to deliver internally more than $26150 \mathrm{~kg}$ of separable payload to the very low and unstable orbit. Subsequently, an orbital transfer is necessary from LEO to GTO.
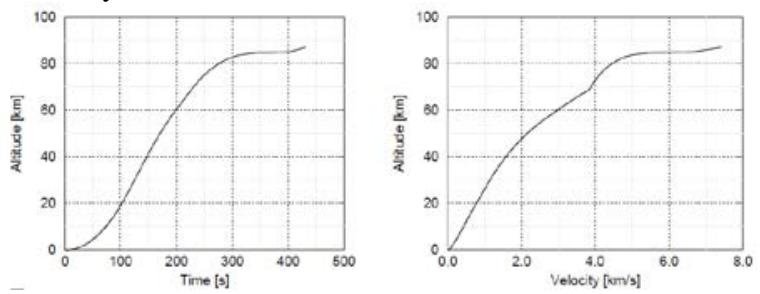

Figure 21: SpaceLiner ascent into $30 \mathrm{~km} \times 250 \mathrm{~km}$ transfer orbit, GTO mission

The SpaceLiner 7 TSTO investigations focus on conventional transfer- or upper stages using high-thrust chemical propulsion. A generic storable propellant upper stage has been selected for payload transfer from $30 \mathrm{~km} \times 250 \mathrm{~km}$ to the $250 \mathrm{~km} \times 35786 \mathrm{~km}$ GTO. The duration of the ballistic phase available for upper stage and payload release starting after Orbiter MECO up to stage ignition in a safe distance is approximately $1600 \mathrm{~s}$. The optimum upper stage propellant loading (combination not yet selected but $\mathrm{I}_{\text {sp }}$ set to realistic 324 s) is slightly above 16 tons which permits a separated satellite mass in GTO of $8250 \mathrm{~kg}$.

Return of the two reusable stages to the launch site is to be assured for any feasible option. The SpaceLiner Orbiter reentry has been simulated with an entry interface speed of approximately $7.37 \mathrm{~km} / \mathrm{s}$. Reaching its once-around destination CSG in Kourou is without problem for the orbiter due to its very good hypersonic L/D well above 2. The vehicle crosses Central America at high altitude and turns to the South over the Caribbean Sea. Almost no sonic boom should be audible on ground. The maximum heatloads remain slightly lower than for the reference passenger concept because of a different AoA-profile and lower vehicle mass. The preliminary assumption of a common TPS with the passenger stage is confirmed.

The SpaceLiner booster stage after separation is performing a gliding reentry and assumed to be carried back by the patented "in-air-capturing"-procedure (description in e.g. [9, 10, 11, 26]). This efficient RLVreturn mode is comparable to the DRL of BFR [26].

\subsection{Passenger mission Earth}

\subsubsection{BFR}

Probably one of the most spectacular announcements at the end of Elon Musk's speech at the IAC 2017 was about using BFR also as an "Earth-to-Earth" or point-topoint passenger transport. Detailed information on the 
realization of this feature is still limited to estimated flight times for several destinations and maximum achieved velocity $[1,2]$. The animated video of an example BFR passenger flight going from New York to Shanghai in 39 minutes [2] provides some information on the flight profile. The BFR ascends in full configuration (booster and BFS) with the booster performing a boostback-burn after its separation, thus probably flying back and landing at the launch site. The BFS continues to accelerate up to $27000 \mathrm{~km} / \mathrm{h}[1,2]$ (or $7500 \mathrm{~m} / \mathrm{s}$ ) and travels in an unspecified trajectory to East-Asia where the BFS lands vertically on a landing pad offshore Shanghai downtown (Figure 1). A major part of the BFS high speed flight is probably at high altitude, a reasonable assumption which is supported by the statement in [1] ".. there is no friction, so once you are out of the atmosphere”.

This information has been taken into account when remodeling the BFR trajectory. However, several more assumptions had to be made by DLR in order to find a potentially feasible trajectory. This brings considerable uncertainty to all simulation results presented in this section. Therefore, it is important to note that the intended actual flight path of BFR/BFS in the Earth-toEarth mission might be different to what is shown here.

Any exact position of a potential launch pad close to NYC is unknown, however, a certain safety distance has to be kept to ensure no third party harm in case of a failure or explosion on the launch pad. Hence, the launch and landing positions in NYC and Shanghai were assumed to be several kilometers from the shore. Moreover, the launch azimuth is selected such that the BFR flies over densely populated regions of the New York City metropolitan area (see Figure 22) which also seems to be supported by the video [2].

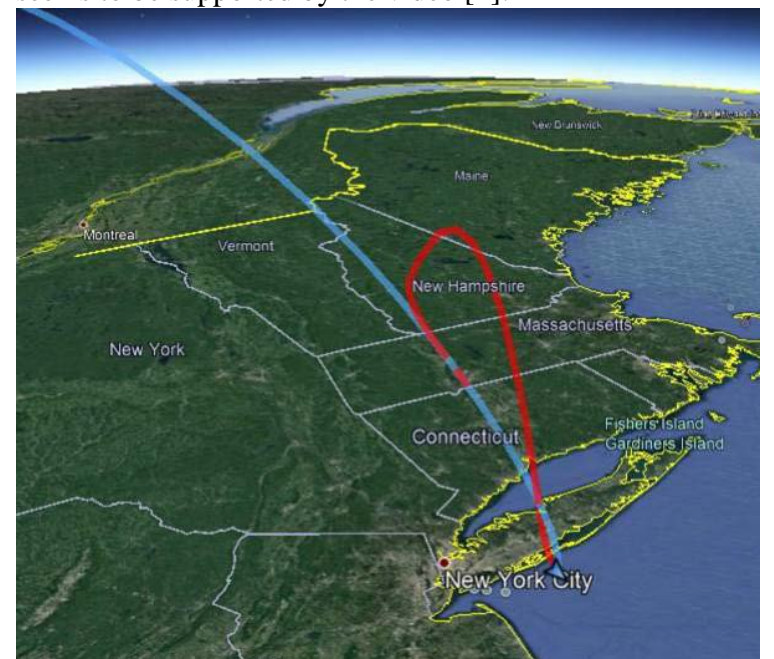

Figure 22: Simulated New York - Shanghai mission ascent (blue) and RTLS maneuver of BFR booster (red)

Typically today, launching over densely populated areas is strictly avoided due to obvious safety and launch noise constraints. However, it seems unlikely that BFR has an alternative option for the NYC - Shanghai mission to be flown in 39 minutes other than the chosen direction of the DLR simulation considering the BFS crossrange capability. One possibility of evading excessive launch noise over continental America could be the placement of the launch platform about $100 \mathrm{~km}$ off- shore and aiming for a steep ascent rapidly reaching very high altitudes avoiding noise reaching ground.

The MECO conditions of the DLR simulation are 7.33 $\mathrm{km} / \mathrm{s}$ in an altitude of $202 \mathrm{~km}$. (Figure 22) Before the BFS performs a gliding, nose-first reentry comparable to the SpaceLiner it travels more than $2500 \mathrm{~km}$ virtually outside of the atmosphere. The vehicle is decelerated by controlling the AoA and bank angle and thus aerodynamic forces. When reaching subsonic speeds, the vehicle is flipped to a vertical orientation and the engines are reignited to slow the BFS down to landing velocities similar to the video animation [2].
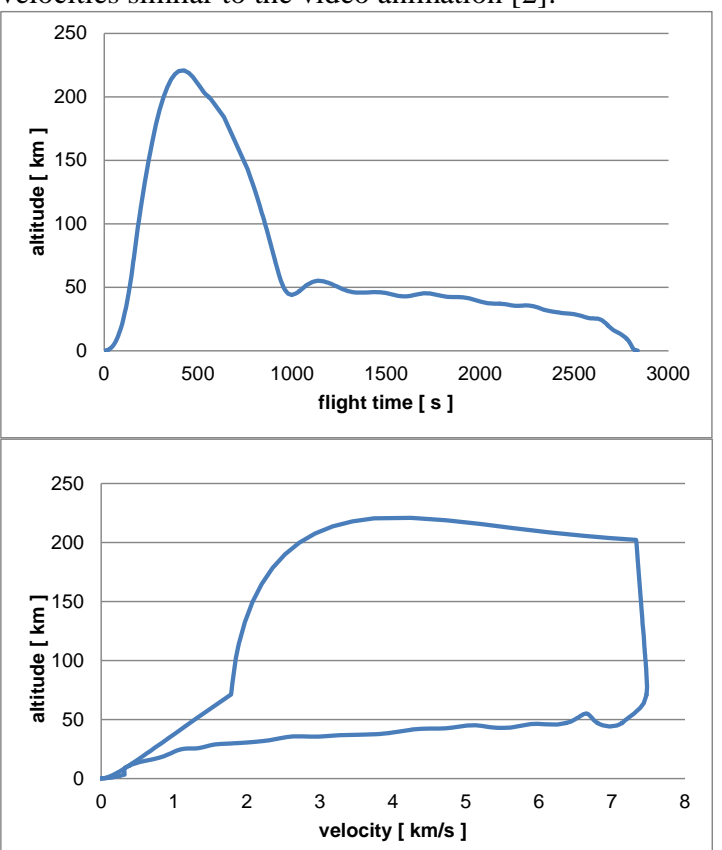

Figure 23: DLR-simulated New York - Shanghai mission profile of BFR

The BFR has a quite steep ascent trajectory permitting reduced propellant demand for the RTLS of the booster stage and limiting noise on populated areas. As a consequence the reentry angles of the BFS become relatively large for limited performance losses. Due to the restricted lift-capability of the BFS the atmospheric deceleration takes place in lower altitudes compared to the SpaceLiner, thus increasing the peak heatload and reducing the possible maximum flight range. The load factors along the flight history are depicted in Figure 24. Maximum acceleration in ascent is up to $4.5 \mathrm{~g}$ but might be reduced by engine throttling. After MECO the BFS is for $340 \mathrm{~s}$ completely weightless before the reentry loads rapidly reach about $1.5 \mathrm{~g}$ in lateral direction and later for powered landing slightly above $2.4 \mathrm{~g}$ in axial direction.

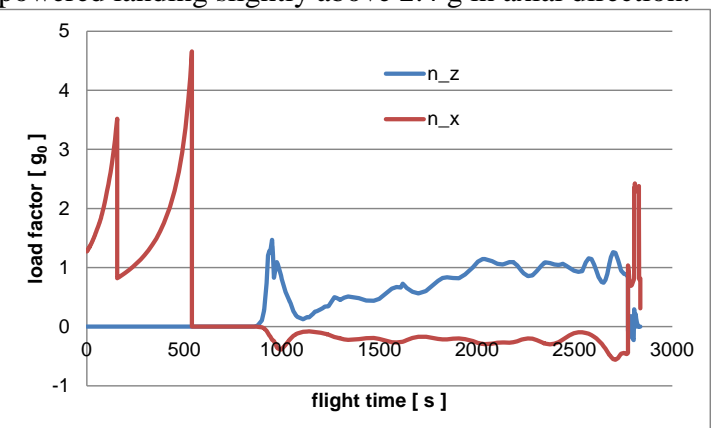

Figure 24: Load factors of DLR-simulated New York - Shanghai mission BFS 
The overall simulated flight time (including ascent) is around 47 minutes; 8 minutes longer than the 39 minutes mentioned in [2]. This $20 \%$ relative deviation seems to be of minor importance because the DLR analysis confirms that such Earth-to-Earth-trajectories could theoretically be feasible. The simulated maximum speed of $7.33 \mathrm{~km} / \mathrm{s}$ remaining below $7.5 \mathrm{~km} / \mathrm{s}$ [1, 2] due to the high uncertainty of DLR's preliminary assumptions is one potential explanation for this deviance.

\subsubsection{SpaceLiner}

The ambitious Australia - Europe mission has been used as the reference case since the beginning of the SpaceLiner investigations [4, 5]. This flight distance should be served for 50 passengers on a daily basis in each direction. Several other, shorter intercontinental missions exist, which potentially generate a larger market demand. For this reason a SpaceLiner configuration derivative has been studied, which could transport up to 100 passengers [16]. In order to keep the number of different stage configurations at the lowest possible level, the potentially interesting flight destinations have been divided into three classes:

- Class 1: Reference mission (up to $17000 \mathrm{~km}$ ) Australia - Europe with 50 passengers orbiter and large reference booster

- Class 2: Mission (up to $12500 \mathrm{~km}$ ) with increased 100 passengers orbiter and large reference booster

- Class 3: Mission (up to 9200 km) e.g. TransPacific with increased 100 passengers orbiter and reduced size booster

These three mission classes could be flexibly served by a suitable combination of four different vehicles (however with a lot of commonality in subcomponents like engines): 50 and 100 passenger orbiter stage and large and shortened booster.

Different trajectory options have been traded in the past mostly for the Australia - Europe reference mission for up to 50 passengers. These were following a standard launch vehicle vertical ascent with an initial azimuth in North-Eastern direction overflying the arctic sea before approaching Europe from the North-Eastern Atlantic. The propulsive phase of approximately 8 minutes duration is directly followed by hypersonic gliding succeeded by landing approach after approximately an additional hour and 20 minutes of flight.

Flight path as well as groundtrack constraints and demands for operationally interesting launch and landing sites influence the selection of practical reference trajectories. The launch and ascent noise as well as the sonic boom reaching ground are most critical for a viable SpaceLiner operation in the future. Therefore, operational scenarios of the SpaceLiner are established taking into account realistic launch- and landing sites as well as groundtracks which are acceptable with respect to sonic boom constraints overflying populated areas and fast accessibility to major business centers. Conventional existing airports located close to densely populated areas are not suitable for SpaceLiner operations. Three alternative launch and landing site concepts should fit for almost all potential locations [19]. Systematic and extensive analyses on worldwide trajectory options beyond the reference mission are ongoing.
The Europe - Australia and return route is still the baseline for other investigations. As a preliminary and currently non-binding assumption, the flight connection is assumed for two on-shore launch landing sites located in Queensland, Eastern Australia and in the German North-Sea-coastal region. Both locations have the advantage of the complete launch ascent and supersonic gliding approach capable of being performed over the sea while still being relatively close to each continent's major business centers. These are two key-requirements for successful future SpaceLiner operation.

The reference mission from Australia to Europe of the SpaceLiner7-3 configuration is fully feasible, meeting all requirements imposed by the vehicle: dynamic pressure, acceleration and heat flux. The covered range is approximately $16000 \mathrm{~km}$ and the simulated flight time no more than 71 minutes to TAEM cylinder before final landing approach. The MECO conditions reached at the end of the ascent flight is approximately $7.2 \mathrm{~km} / \mathrm{s}$ in an altitude of $73.1 \mathrm{~km}$ and the flight path angle $\gamma$ is close to $0^{\circ}$. The corresponding maximum Mach number is slightly beyond 25 and approximately $9000 \mathrm{~km}$ (more than $50 \%$ of the overall distance) are flown at Mach numbers larger than 20 (Figure 25).

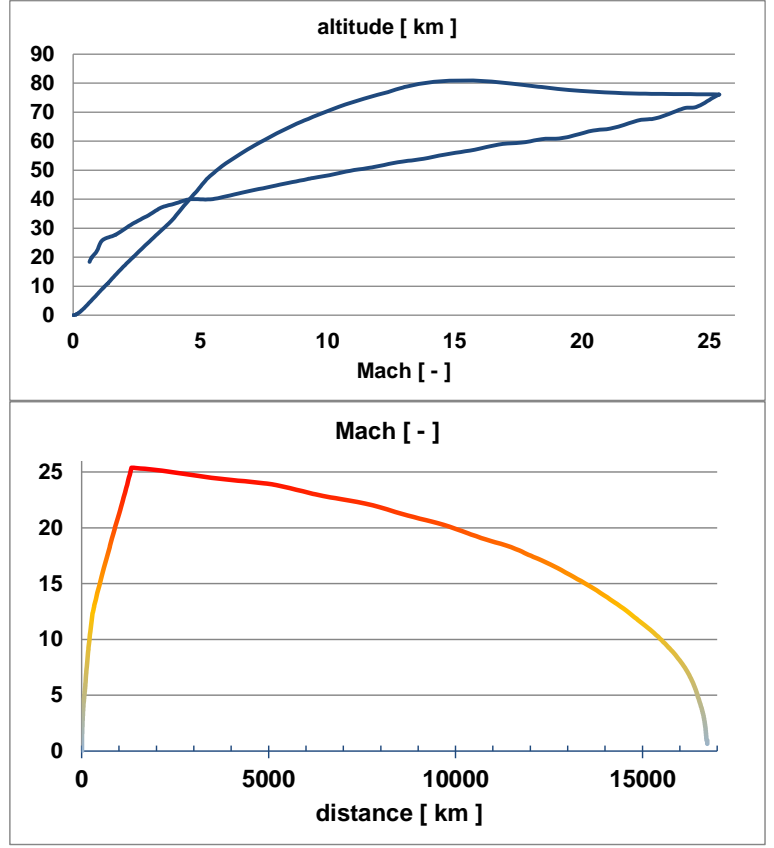

Figure 25: SpaceLiner 7-3 simulated ascent and descent trajectory data for nominal mission Australia to Europe

The descent ground track of the nominal reference mission is shown in [27]. Noise and sonic boom impact on inhabited areas is very low and actual proof of full public acceptability of the vehicle flying at very high altitude is under assessment.

Figure 26 shows the loadfactors acting on the SpaceLiner during a nominal Europe to Australia mission. Due to engine throttling by MR-change and sequential engine shut-down on the booster stage the axial load in the ascent phase is not exceeding $2.5 \mathrm{~g}$. SpaceLiner passengers are never in complete weightlessness because the large wing is still generating some lift even in $75 \mathrm{~km}$ altitude. Thus, the normal load has its minimum with 0.2 g right after MECO and afterwards is smoothly approa- 
ching the $1 \mathrm{~g}$ conditions in subsonic flight or on ground. The axial deceleration is benign, never exceeding $-0.1 \mathrm{~g}$.

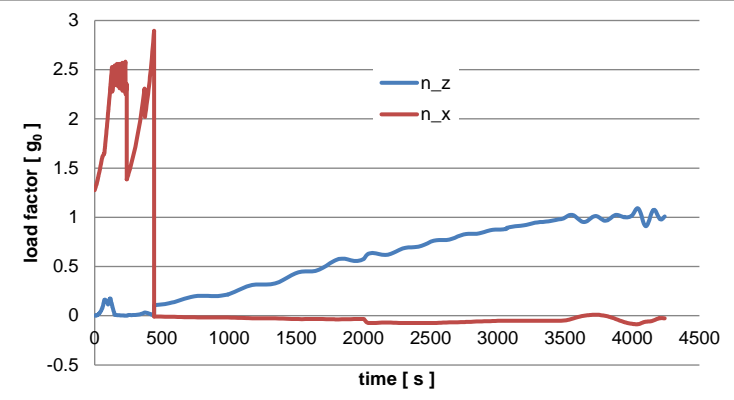

Figure 26: Load factors on SpaceLiner 7-3 nominal passenger mission Europe to Australia

Considering the large market potential an ultrafast mission from East Asia to Europe is highly interesting. Assuming the same European launch and landing site it is not easy to find a counterpart in the far eastern region. Places in the Eastern China or Korean coastal areas had to be discarded because not finding trajectories for which ascent noise is not interfering with densely populated areas. A potentially feasible option for the site could be in the Japanese Sea from which also the TransPacific route to America could be served (Figure 27).

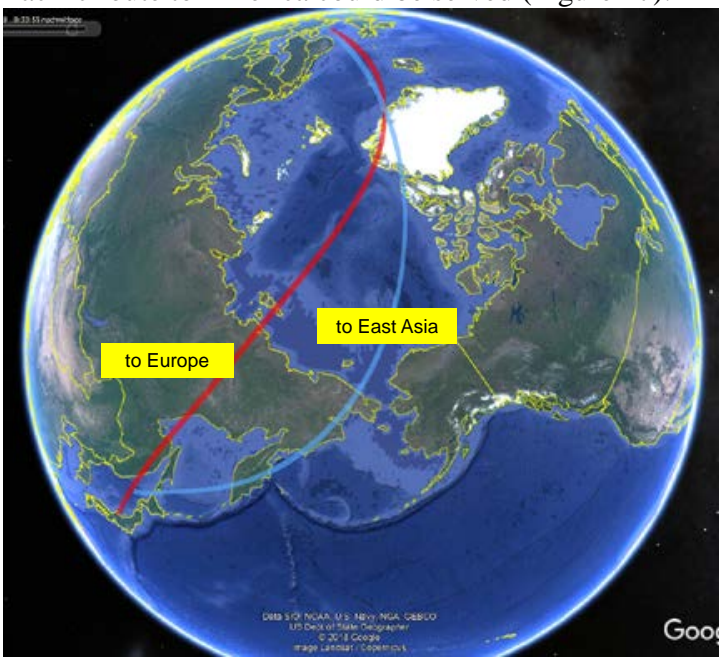

Figure 27: Potential groundtracks of SpaceLiner 7-3 nominal passenger missions Europe to East-Asia

The flight route from Australia to North-East America is found even more difficult and challenging to be achieved under similar constraints. Although it is possible to reach the East Coast of the United States, either approaching from the north or the south, the assumed potential launch sites for return trajectories were not suitable to complete the mission. The proposal for a new launch site on the west coast of Florida seems to be most promising for the North East America Australia mission. However, this option might cause problems during the ascent phase over a highly traffic loaded area (Gulf of Mexico) [27].

Regarding the shorter distance Europe to California mission using the SpaceLiner 100-passengers version [16], the simulated trajectories [27] under consideration are preliminary. The chosen ascent trajectory for this case has a significantly different altitude profile than the previously investigated variants. The maximum reached altitude goes beyond $100 \mathrm{~km}$ whereas the final velocity is only slightly above $6 \mathrm{~km} / \mathrm{s}$ due to the heavier upper stage and the shorter flight distance required [27].

An alternative option already discussed in [27] is a trajectory with a few degrees of $\gamma$ in the MECO point which would result in a ballistic arc duration of a couple of minutes for the SpaceLiner. The vehicle would travel during this phase more than $1000 \mathrm{~km}$ almost outside of the atmosphere at very low drag. However, in order to avoid excessive heatrates, an increased angle-of-attack is subsequently needed at lower altitude which has a strongly decelerating effect. A definitive answer on the best trajectory requires detailed system studies taking into account flight path optimization, adapted TPSsizing, and reliable data on the friction drag in low atmospheric density.

\subsection{Cost Issues}

The key-interest in the multiple mission reusable launch vehicles is the potential cost reduction in development and operations. A much more detailed analysis of all potential missions under different operational scenarios would be required before a quantitative assessment could become meaningful. This task is reaching far beyond the aim of this paper. Therefore, only a few costrelated issues will be discussed here.

Elon Musk is explicitly talking about cost issues of very large multiple mission fully reusable rockets in reference 1: "Due to full reusability, BFR provides lowest marginal cost per launch, despite vastly higher capacity than existing vehicles." This kind of paradigm shift in the launcher business, off-course, is only possible if full reusability with a sufficient number of reuses and also limited recovery and refurbishment costs can be realized. A target recurring cost of $8 \mathrm{MSUS}$ per BFR flight is speculated which roughly reflects the cost of propellants and ground operations.

An extensive study at DLR on SpaceLiner related costs has been published [30] giving a detailed description from which important results are summarized in [27]. The SpaceLiner development and operations should be funded mostly by private investment. Forms of private public partnerships are potential options. In any case a reliable estimation of to-be-expected costs during development, production, and operations is already required early in the technical design process before a market oriented development can be performed.

Based on the production cost assessment of the passenger transport with more than 30 vehicles and over 2000 engines produced per year in the baseline worldwide operational scenario, the production and, subsequently, the launch cost of the SpaceLiner TSTO can be estimated. The satellite launcher components should be manufactured on the same line as those of the passenger vehicle [27]

Assuming an airframe life-time of 150 missions and 25 missions per engine, further taking into account additional costs for maintenance, refurbishment, satellite launch preparation, and (if needed) for an expendable kick-upper stage, the launch cost has been calculated [27]. The GTO-mission cost is well below $15 \mathrm{M} €$ and the LEO-(ISS-resupply)mission cost without expendable stage is significantly below $10 \mathrm{M} €$. These values 
translate into attractive specific launch cost of less than $2000 € / \mathrm{kg}$ and less than $1000 € / \mathrm{kg}$ under conservative assumptions.

These cost assessments obtained completely independent of the BFR data for a much smaller vehicle confirm the principal cost saving potential of multiple-mission RLV. This major improvement might allow creating new business opportunities in space which are not affordable with today's infrastructure.

\section{CONCLUSION}

Multiple mission reusable launch vehicles are new and promising concepts for future space transportation roles. The SpaceX concept BFR with vertical take-off vertical landing characteristics and the DLR SpaceLiner with vertical take-off - horizontal landing characteristics are two typical examples.

The concepts BFR and SpaceLiner show several similarities but also major differences in their design solutions. Both concepts are fully reusable TSTO but stage arrangement and propellant choice are different. While BFR stages are in tandem configuration loaded with LOX-LCH4, the SpaceLiner has a parallel stage architecture and LOX-LH2. However, the type of main propulsion system is quite similar with both configurations using staged combustion cycle (FFSC) propulsion.

The total lift-off mass of the SpaceLiner is slightly above $2000 \mathrm{Mg}$ while that of the BFR (2017) is above $4300 \mathrm{Mg}$ because of its increased payload performance requirement and lower Isp. The structural indices of the SpaceLiner stages are significantly above BFR because of large tank structures due to low density hydrogen and mainly due to the intentionally robust design philosophy of the concept with emergency rescue system for the passengers.

The BFR payload performance to LEO as fully reusable TSTO is depending on the first stage return mode and stage dry masses. The DLR analyses do not fully confirm the 150 tons payload target for which, however, exact orbit data are not publicly available. A reusable TSTO satellite transport version of the SpaceLiner with internal cargo bay but overall similar lay-out to the passenger transport has been defined. Iterative design with simulation of all stage's trajectories demonstrate that larger than 8.2 tons separated satellite mass can be lifted into GTO when using an additional expendable kick-stage. Simulations proof that the SpaceLiner TSTO version stays within the load constraints of the PAXversion which confirms that the baseline design can be reused without major development effort.

Potential worldwide passenger flight routes under realistic operational and environmental constraints are evaluated for the SpaceLiner concept. A comparable intercontinental connection of the BFR/BFS from New York to Shanghai has been modeled by DLR. The principal achievability of its announced flight time is confirmed. The passenger safety concept of SpaceX' BFS is unknown as are the BFR's on ground and noise (sonic boom) constraints.
Potentially, both concepts offer dramatic launch cost reduction by reusability and serial production of hardware. Based on the production cost assessment of the passenger transport, attractive specific launch cost of less than $2000 € / \mathrm{kg}$ in GTO and less than $1000 € / \mathrm{kg}$ in LEO are achievable for the SpaceLiner. In case of the significantly larger BFR the specific payload transportation costs could be even lower.

The technical comparison of the SpaceX BFR proposal in its 2017 configuration with the DLR SpaceLiner 7 reveals a considerably more ambitious approach of the US-concept in the fields of propulsion, structure, weight and aerothermodynamics. The SpaceLiner, somehow less demanding, could still become a challenging endeavor for Europe.

\section{ACKNOWLEDGEMENTS}

The authors gratefully acknowledge the contributions of Ms. Carola Bauer, Ms. Mona Carlsen, Ms. Elena Casali, Ms. Nicole Garbers, Ms. Carina Ludwig, Ms. Sarah Lipp, Ms. Olga Trivailo, Ms. Cecilia Valluchi, Mr. Alexander Kopp, Mr. Ryoma Yamashiro, Mr. Jascha Wilken, Mr. Magni Johannsson, Mr. David Gerson, Mr. Jochen Bütünley, Mr. Sven Krummen, Mr. Leonid Bussler, and Mr. Sholto Forbes-Spyratos to the analyses and preliminary design of the SpaceLiner.

\section{REFERENCES}

1. Musk, E.: Making Life Multi-Planetary, in NEW SPACE, VOL. 6, NO. 1, 2018 DOI: 10.1089/space.2018.29013.emu

2. https://www.youtube.com/watch?v=zqE-ultsWt0

3. N.N.: BECOMING A MULTIPLANET SPECIES, presentation by SpaceX, 2017

4. Sippel, M., Klevanski, J., Steelant, J.: Comparative Study on Options for High-Speed Intercontinental Passenger Transports: Air-Breathing- vs. RocketPropelled, IAC-05-D2.4.09, October 2005

5. Sippel, M., Klevanski, J., van Foreest, A., Gülhan, A., Esser, B., Kuhn, M.: The SpaceLiner Concept and its Aerothermodynamic Challenges, $1^{\text {st }}$ ARADays, Arcachon July 2006

6. Sippel, M.: Promising roadmap alternatives for the SpaceLiner, Acta Astronautica, Vol. 66, Iss. 11-12, (2010)

7. Sippel, M.; Schwanekamp, T.; Trivailo, O.; Lentsch, A.: Progress of SpaceLiner RocketPowered High-Speed Concept, IAC-13-D2.4.05, IAC2013, Beijing, September 2013

8. Van Foreest, A. , Sippel, M.; Gülhan, A.; Esser, B.; Ambrosius, B.A.C.; Sudmeijer, K.: Transpiration Cooling Using Liquid Water, Journal of Thermophysics and Heat Transfer, Vol. 23, No. 4, October-December 2009

9. Sippel, M.; Klevanski, J.; Kauffmann, J.: Innovative Method for Return to the Launch Site of Reusable Winged Stages, IAF-01-V.3.08, 2001

10. Sippel, M.; Klevanski, J.: Simulation of Dynamic Control Environments of the In-Air-Capturing Mechanism, $6^{\text {th }}$ International Symposium on Launcher Technology 2005, B1.4 
11. Sippel, M.; Bussler, L; Krause, S.; Cain, S.: Bringing Highly Efficient RLV-Return Mode "InAir-Capturing” to Reality, HiSST 2018-1580867, $1^{\text {st }}$ HiSST: International Conference on High-Speed Vehicle Science Technology, Moscow, to be published November 2018

12. Musk, E.: Making Humans a Multi-Planetary Species, in NEW SPACE, VOL. 5, NO. 2, 2017, DOI: 10.1089/space.2017.29009.emu

13. Sippel, M., Wilken J.: Preliminary Component Definition of Reusable Staged-Combustion Rocket Engine, Space Propulsion 2018, Seville, May 2018

14. Schwanekamp, T.; Bauer, C.; Kopp, A.: The Development of the SpaceLiner Concept and its Latest Progress, $4{ }^{\mathrm{TH}}$ CSA-IAA CONFERENCE ON ADVANCED SPACE TECHNOLOGY, Shanghai, September 2011

15. Yamashiro, R.; Sippel, M.: Preliminary Design Study of Staged Combustion Cycle Rocket Engine for SpaceLiner High-Speed Passenger Transportation Concept, IAC-12-C4.1.11, Naples, October 2012

16. Schwanekamp, T.; Bütünley, J.; Sippel, M.: Preliminary Multidisciplinary Design Studies on an Upgraded 100 Passenger SpaceLiner Derivative, AIAA2012-5808, 18 ${ }^{\text {th }}$ AIAA International Space Planes and Hypersonic Systems and Technologies Conference, Tours, September 2012

17. Bauer, C.; Garbers, N.; Sippel, M.: The SpaceLiner 7 - Vehicle and Rescue Capsule, ISTS, Nagoja 2013

18. Stappert, S.; Sippel, M.; Bussler, L.; Wilken, J.; Krummen, S.: SpaceLiner Cabin Escape System Design and Simulation of Emergency Separation from its Winged Stage, AIAA 2018-5255, $22^{\text {nd }}$ AIAA International Space Planes and Hypersonic Systems and Technologies Conference, 17-19 September 2018, Orlando, Florida, USA

19. Sippel, M.; Schwanekamp, T; Trivailo, O; Kopp, A; Bauer, C; Garbers, N.: SpaceLiner Technical Progress and Mission Definition, AIAA 20153582, $20^{\text {th }}$ AIAA International Space Planes and Hypersonic Systems and Technologies Conference, Glasgow, July 2015

20. Sippel, M.; Schwanekamp, T.; Ortelt, M.: Staged Combustion Cycle Rocket Engine Subsystem Definition for Future Advanced Passenger Transport, Space Propulsion 2014, Cologne, Germany, May 2014

21. Schwanekamp, T.; Ludwig, C.; Sippel, M.: Cryogenic Propellant Tank and Feedline Design Studies in the Framework of the CHATT Project, $19^{\text {th }}$ AIAA International Space Planes and Hypersonic Systems and Technologies Conference, AIAA Aviation and Aeronautics Forum and Exposition, June 2014

22. Sippel, M.; Schwanekamp, T.: The SpaceLiner Hypersonic System - Aerothermodynamic Requirements and Design Process, $8^{\text {th }}$ European Symposium on Aerothermodynamics for Space Vehicles, Lisbon, March 2015

23. Bonetti, D. et al: Hypersonic Morphing for a Cabin Escape System: Results of First Design Loop, $8^{\text {th }}$
European Symposium on Aerothermodynamics for Space Vehicles, Lisbon 2015

24. Schwanekamp, T.; Mayer, F.; Reimer, T.; Petkov, I.; Tröltzsch, A.; Siggel, M.: System Studies on Active Thermal Protection of a Hypersonic Suborbital Passenger Transport Vehicle, AIAA Aviation Conference, AIAA 2014-2372, Atlanta, June 2014

25. Bauer, C.; Kopp, A.; Schwanekamp, T.; Clark, V.; Garbers, N.: Passenger Capsule for the SpaceLiner, DLRK-paper, Augsburg 2014

26. Sippel, M.; Stappert, S.; Bussler, L.: "Systematic Assessment of a Reusable First-stage Return Options”, IAC-17-D2.4.4, 68 ${ }^{\text {th }}$ International Astronautical Congress, Adelaide, Australia, 25-29 September 2017, http://elib.dlr.de/114960/

27. Sippel, M., Trivailo, O., Bussler, L., Lipp, S., Kaltenhäuser, S.; Molina, R.: Evolution of the SpaceLiner towards a Reusable TSTO-Launcher, IAC-16-D2.4.03, September 2016

28. Sippel, M.; Bussler, L.; Kopp, A.; Krummen, S.; Valluchi, C.; Wilken, J.; Prévereaud, Y.; Vérant, J.L.; Laroche, E.; Sourgen, E.; Bonetti, D.: Advanced Simulations of Reusable Hypersonic RocketPowered Stages, AIAA 2017-2170, $21^{\text {st }}$ AIAA International Space Planes and Hypersonic Systems and Technologies Conference, 6-9 March 2017, Xiamen, China

29. Ponomarenko, A.: RPA - Tool for Rocket Propulsion Analysis, Space Propulsion 2014, Cologne, Germany, May 2014

30. Trivailo, O.: Innovative Cost Engineering Analyses and Methods Applied to SpaceLiner - an Advanced, Hypersonic, Suborbital Spaceplane Case-Study, PhD Thesis 2015

31. Trivailo, O. et.al.: SpaceLiner Mission Requirements Document, SL-MR-SART-00001$1 / 2$, Issue 1, Revision 2, SART TN-005/2016, 11.07.2016

Further updated information concerning the SART space transportation concepts is available at: http://www.dlr.de/SART 